UNCLASSIFIED: Distribution Statement A.

Approved for public release

\title{
Effects of fuel physical properties on direct injection spray and ignition behavior
}

Doohyun Kim, ${ }^{\text {a Jason Martz, }}{ }^{\mathrm{a}}$ Angela Violi ${ }^{\mathrm{a}, \mathrm{b}}$

${ }^{a}$ Department of Mechanical Engineering, University of Michigan, 2350 Hayward St., Ann Arbor, MI 48109

${ }^{\mathrm{b}}$ Department of Chemical Engineering, Macromolecular Science and Engineering, Biophysics Program, University of Michigan, 2350 Hayward St., Ann Arbor, MI 48109

Corresponding author: Angela Violi (avioli@umich.edu)

2350 Hayward St., Ann Arbor, MI 48109-2125

(734) $615-6448$ 


\title{
UNCLASSIFIED
}

\begin{abstract}
CFD simulations of reacting fuel sprays were conducted to identify temperaturedependent physical properties of the liquid fuel that should be emulated by diesel and jet fuel surrogates within simulations of compression ignited combustion. Using a validated CFD model for an n-dodecane spray under diesel-relevant conditions, six physical properties of the liquid phase fuel (density, vapor pressure, viscosity, surface tension, heat of vaporization, and specific heat capacity) were perturbed covering the minimum and maximum property range of hydrocarbons widely used in recent diesel and jet fuel surrogates. Liquid fuel density, viscosity, vapor pressure, and specific heat had significant impact on liquid penetration length, causing a $4 \%$ $\sim 16 \%$ change from the baseline n-dodecane case. The changes resulted from the liquid fuel's influence on various physical phenomena, including droplet breakup, air entrainment and evaporation. For ignition delay, specific heat and density effects were most significant, with up to $10 \%$ changes from the baseline case. Specific heat perturbations affected the thermal energy necessary for fuel vaporization, hence local temperature development and mixture reactivity. Liquid density influenced the velocity of the fuel injection event, which modified turbulent mixing rates, low temperature heat release characteristics and the transition to high temperature ignition. The results of this study indicate that liquid density, specific heat, viscosity, and vapor pressure should be considered for surrogate development to properly capture the liquid penetration and ignition delay characteristics of the target fuel.
\end{abstract}

Keywords: liquid penetration, ignition delay, spray simulation, CFD 


\section{UNCLASSIFIED}

\section{Introduction}

Typical fuels used in internal combustion engines, such as gasoline, diesel, or jet fuel, are composed of hundreds to thousands of hydrocarbon (HC) species. Using such a large number of species in high fidelity Computational Fluid Dynamics (CFD) simulations with detailed chemistry is beyond our current computational capability. Therefore, surrogate fuels and their associated chemical mechanisms have been developed and utilized to represent the combustion behavior of typical HC fuels within CFD simulations. Surrogate formulation approaches seek to overcome this challenge by matching the combustion related properties of the target fuel with a much smaller number of representative fuel species [1-6]. This approach requires reliable models of the $\mathrm{HC}$ mixture properties for mathematical optimization to determine the surrogate composition that best represents the target fuel properties. For modern compression ignited diesel engines, which employ direct fuel injection, the physical properties of liquid fuel influence the spray, mixture development and ultimately the ignition and combustion process [7]. To this end, it is very important to understand which fuel properties impact combustion within the targeted device in order to emphasize these properties in future surrogate formulations.

To date, most studies into the importance of liquid fuel physical properties to compression ignited combustion behavior have been experimental. Studies by Naber and Siebers [8] and Siebers $[9,10]$ investigated the effect of various parameters on liquid penetration and observed that lower fuel volatility resulted in longer liquid length. Higgins et al. [11] tested nine different fuels and proposed a liquid penetration correlation as a function of fuel density and the energy required to vaporize the liquid fuel. Genzale et al. [12] compared diesel and biodiesel sprays under conditions relevant to late-cycle post-injection and showed $\sim 15 \%$ longer liquid penetration lengths for biodiesel. Kook and Pickett [13] tested a variety of jet fuels and showed that while the variations in vapor penetration lengths of the different fuels were within the experimental uncertainties, liquid penetration length was affected by liquid density and volatility. Payri et al. [14] investigated the influence of fuel temperature on the liquid penetration, lift-off 


\section{UNCLASSIFIED}

length and ignition delay of diesel sprays. Wu et al. [15] observed that the viscosity of oxygenated fuels influenced spray atomization behavior. Other experimental comparisons have been made to assess the sensitivity of engine performance, emissions, and spray characteristics to the properties of alternative diesel fuels, such as dimethyl ether (DME), biodiesel, and jet fuel, which are significantly different from those of petroleum derived diesel fuel [16-20].

While these experiments provided valuable insights, it is difficult to isolate the effect of each property by comparing results from experiments where several fuel physical properties are varying simultaneously. Computational studies can be used to isolate these effects and their influence on the complex processes occurring during spray combustion. Only a limited number of numerical investigations have examined liquid fuel property effects, including the work of Som et al. [21], which quantified the differences between the injection and spray characteristics of biodiesel and diesel fuel. Pei et al. [22] conducted a sensitivity analysis with a diesel engine simulation to assess the relative effects of various physical properties including density, heat of vaporization, vapor pressure, and viscosity. While parameters other than fuel properties (such as select model constants and injector-related parameters) were shown to be the most sensitive variables, the liquid fuel density was shown to affect ignition delay, combustion phasing, and emissions. CFD simulations by Ra et al. [23] predicted that density, vapor pressure, and surface tension had the largest effect on cylinder pressure and combustion phasing. However, this study focused on engine performance parameter sensitivity rather than on understanding how physical property variations affect spray formation and ignition behaviors.

This paper investigates the effects of temperature-dependent liquid fuel physical properties (such as density and viscosity) on spray penetration, the evolution of local thermodynamic states within the jet, and the ignition delay period of compression ignited combustion. These effects are predicted using a validated CFD simulation of a free fuel jet. Through such efforts, the surrogate optimization processes can be better informed during the development of future surrogate fuels. 


\section{UNCLASSIFIED}

\section{Model Configuration}

Spray characteristics were predicted under diesel-relevant conditions with the CFD package CONVERGE [24]. The Reynolds Averaged Navier Stokes (RANS) equations with the RNG k- $\varepsilon$ model were utilized to model the turbulence in the gas-phase flow field. Automatic mesh refinement and fixed embedding near the nozzle were used to increase the solution's spatial resolution with a minimum increase in computational expense [24].

The two-phase processes within the spray were modeled with the Lagrangian-Droplet and Eulerian-Fluid approach. The dynamics of the fuel spray droplet were described with a number of phenomenological and physical models. The blob injection method of Reitz and Diwakar [25] was employed. The Kelvin-Helmholtz - Rayleigh-Taylor (KH-RT) model, without the use of an ad hoc breakup length definition, was used to predict the breakup and atomization of the injected fuel parcels [24]. Liquid droplet collision and coalescence was modeled with the No Time Counter collision model [26] in conjunction with the Post collision outcome model [27]. The dynamic drop drag model of Liu et al. [28] was utilized to account for the change of the drag coefficient due to droplet deformation. A standard droplet turbulent dispersion model [29] was included, while droplet evaporation was predicted with the Frossling correlation [29]. These spray submodels depend on the liquid physical properties and have been validated for a wide range of fuels with drastically different physical properties, such as DME, large alkanes, diesel fuel, and biodiesel [21,30-32]. Based on the work of Senecal et al. [33] that showed asymptotic convergence of the spray characteristics with grid refinement, the minimum grid size in the adaptive mesh refinement algorithm and the total number of injected parcels were set to $0.25 \mathrm{~mm}$ and 512,000, respectively; the base mesh size was $2 \mathrm{~mm}$.

Pure n-dodecane, which is often used as an n-alkane representative within jet and diesel fuel surrogates $[34,35]$, was used as the fuel in the current work. Temperature-dependent liquid n-dodecane physical properties were taken from the DIPPR database [36]. A recently published reduced mechanism with 255 species and 2289 reactions was used to model n-dodecane 


\section{UNCLASSIFIED}

oxidation [37]. The mechanism was validated against several experimental data sets reported in [37], including ignition delay times from shock tube and rapid compression machine studies, species time histories obtained from shock tube experiments, concentration profiles from a pressurized flow reactor, and laminar flame speed. Specifically, the ignition delay times calculated with the mechanism were shown to follow the experimental measurements over a wide range of temperatures $(750 \mathrm{~K} \sim 1400 \mathrm{~K})$, pressures $(12 \mathrm{~atm} \sim 46 \mathrm{~atm})$ and equivalence ratios $(\Phi=0.5 \sim 1)$.

\section{Model Validation}

The model was validated by comparison with experimental data from a constant-volume combustion vessel at Sandia National Laboratories [38-40] that utilized the Spray A injector (serial number 210677). The computational mesh was a $108 \mathrm{~mm}$ cubic chamber, which was identical to the geometry of Sandia's combustion vessel. Liquid/vapor penetration lengths and vaporized fuel mass fraction distributions from two non-reacting spray experiments (ambient conditions of $900 \mathrm{~K} 6.1 \mathrm{MPa} 22.8 \mathrm{~kg} / \mathrm{m}^{3}$ and $1100 \mathrm{~K} 5.0 \mathrm{MPa} 15.2 \mathrm{~kg} / \mathrm{m}^{3}$ ) were used, along with ignition location and ignition delay times from three reacting spray experiments at ambient density of $22.8 \mathrm{~kg} / \mathrm{m}^{3}(750 \mathrm{~K} 4.9 \mathrm{MPa}, 900 \mathrm{~K} 6.1 \mathrm{MPa}$, and $1200 \mathrm{~K} 7.9 \mathrm{MPa})$. The ambient temperatures and pressures of the validation cases are relevant to the ignition conditions within diesel engines. More details of the n-dodecane spray experiments are summarized in Table 1. The injector specifications, the rate of injection profile and all of the simulation boundary conditions were taken from the experiments. In the CFD simulations, the liquid penetration length was defined as the axial distance from the nozzle exit to the region that encompassed the 95th percentile of the total liquid fuel mass at a given time, while the vapor penetration length was defined as the maximum axial distance from the nozzle exit to where the fuel mass fraction is $0.1 \%$. The ignition delay in the simulations was defined as the time between start of the injection and the maximum rise rate of peak temperature [22]. 


\section{UNCLASSIFIED}

Figure 1 shows good agreement between the predicted and experimental liquid and vapor penetration lengths as a function of time for non-reacting spray simulations. The uncertainties associated with the experimental measurements were less than $1 \mathrm{~mm}$ for the bulk of this data [38]. While improvements are necessary in the initial liquid length predictions, the model is able to predict stabilized liquid penetration lengths and overall vapor penetration trends. The root mean squared errors of the stabilized liquid penetration and vapor penetration lengths were $0.4 \mathrm{~mm}$ and $2.8 \mathrm{~mm}$ for the $900 \mathrm{~K}, 22.8 \mathrm{~kg} / \mathrm{m}^{3}$ case, and $0.8 \mathrm{~mm}$ and $2.9 \mathrm{~mm}$ for the $1100 \mathrm{~K}$, $15.2 \mathrm{~kg} / \mathrm{m}^{3}$ case.

The steady-state radial and axial distributions of the vapor fuel mass fraction are compared in Figure 2, again for the non-reacting cases. The simulation results were taken at 2.5 ms after the start of injection, when the mixing fields shown in Figure 2 are steady. As shown in Figure 2, the model was capable of capturing the general radial and axial fuel vapor distribution trends. At $25 \mathrm{~mm}$ downstream from the injector tip, the predicted radial mass fractions for the two test cases were largely within the experimental uncertainties. For the axial distributions at the jet centerline, the fuel vapor mass fraction for the $900 \mathrm{~K}, 22.8 \mathrm{~kg} / \mathrm{m}^{3}$ case was within the experimental uncertainties from $\sim 20 \mathrm{~mm}$ to $\sim 30 \mathrm{~mm}$, however the fuel vapor mass fraction was under-predicted for larger axial distances. The calculated axial vapor fuel mass fraction was in better agreement with the experiments for the $1100 \mathrm{~K}, 15.2 \mathrm{~kg} / \mathrm{m}^{3}$ case. The discrepancy between the experiments and the calculated vapor fuel distribution may result from the spray submodels, the RANS turbulence model and the uncertainties associated with the injection related parameter measurements (injection pressure, injection velocity, etc.).

For the reacting spray simulations, the n-dodecane reaction mechanism [37] was included without changing any of the spray model parameters used in the non-reacting set up. All of the ambient conditions were taken from the experiments, with the exception of the ambient temperature of $750 \mathrm{~K}, 22.8 \mathrm{~kg} / \mathrm{m}^{3}$ case, which needed to be increased by $30 \mathrm{~K}$ for agreement with the experimental ignition delay time. Figure 3 shows the ignition delays from the simulation and the experiments. Although ignition delay times were slightly over-predicted, the model was 


\section{UNCLASSIFIED}

capable of capturing the ignition delay trend over a wide range of temperatures. To validate the spatial ignition location, Figure 4 compares high temperature chemiluminescence images from the experiments to the local temperatures from simulation. As can be seen for all three cases, the model was capable of qualitatively predicting the spatial location of high temperature chemiluminescence, with the highest temperature regions near the start of the ignition.

These comparisons show that the model successfully captures the experimental liquid and vapor penetration lengths, the spatial fuel vapor distribution at steady state for non-reacting spray, along with the ignition delay time and ignition location for reacting sprays. This modeling set up is used as the baseline for the following simulations where the physical properties of the liquid fuel are perturbed.

\section{Liquid Physical Property Perturbation Methodology}

A sensitivity analysis was conducted with reacting spray simulations at two ambient conditions $\left(900 \mathrm{~K}, 22.8 \mathrm{~kg} / \mathrm{m}^{3}\right.$, and $750 \mathrm{~K}, 22.8 \mathrm{~kg} / \mathrm{m}^{3}$ ) to identify the liquid fuel properties that are of significance to the liquid spray penetration length and ignition delay. The vapor penetration length was not analyzed in detail here, given that the change in vapor penetration due to fuel liquid physical property perturbation was very small in the simulations, which is consistent with the experimental observations in Kook and Pickett [13], where the variation in vapor penetration length for fuels with different liquid properties was shown to be smaller than the experimental uncertainties.

Six liquid physical properties appearing in the spray models of the current work were examined, including density, vapor pressure, viscosity, surface tension, heat of vaporization, and specific heat capacity. Beginning with the baseline n-dodecane properties, the individual fuel properties were perturbed one at a time by multipliers which were determined to cover the minimum and maximum property values of the various hydrocarbons used in recent diesel and jet fuel surrogate studies [1-3]. n-heptane, n-decane, iso-octane and iso-cetane were considered 


\section{UNCLASSIFIED}

for linear alkanes; methylcyclohexane and decalin for cycloalkanes; and toluene, 1,3,5trimethylbenzene and n-propylbenzene for aromatics. Figure 5 illustrates this method applied to the perturbation of viscosity. Among the pure hydrocarbons considered here, iso-cetane has the highest viscosity, while $n$-heptane has the lowest. The perturbation of n-dodecane viscosity was determined to cover the range of viscosities of iso-cetane and n-heptane. A similar method was applied to other physical properties. The reason for implementing this method rather than the more conventional approach of using consistent relative changes of each property was that the properties considered in this study have a drastically different range of magnitudes among the various species. For example, decalin has the highest density among the above pure components, which is about $20 \%$ greater than that of n-dodecane. However, n-heptane has highest vapor pressure, which is $10 \sim 20$ times greater than that of $n$-dodecane, depending on temperature. Due to this significant difference among the properties, perturbing the properties with a common multiplier does not represent the real property variations within the surrogate components. Therefore, multiplier perturbations of varying relative differences were performed with this approach and are summarized in Table 2 .

The modeling parameters were maintained from the baseline case for all of the perturbation simulations, with the exception of the injected fuel mass flow rate and the injection velocity for the density perturbation study. The relationship among the mass flow rate $\left(\dot{m}_{f u e l}\right)$, the fuel injection velocity $\left(U_{f u e l}\right)$, the pressure drop across orifice $\left(P_{f u e l}-P_{a m b}\right)$, the momentum flow rate of the liquid fuel through the orifice $\left(\dot{M}_{f u e l}\right)$, and liquid fuel density $\left(\rho_{f u e l}\right)$ can be expressed using mass conservation and Bernoulli's equation, as shown in $[8,38]$ :

$$
\dot{m}_{\text {fuel }}=C_{d} \cdot A_{\text {orifice }} \cdot \sqrt{2 \cdot\left(P_{\text {fuel }}-P_{\text {amb }}\right) \cdot \rho_{\text {fuel }}}
$$




$$
\begin{aligned}
& U_{\text {fuel }}=\sqrt{\frac{2 \cdot\left(P_{\text {fuel }}-P_{a m b}\right)}{\rho_{\text {fuel }}}} \\
& \dot{M}_{\text {fuel }}=\dot{m}_{f u e l} \cdot U_{\text {fuel }} \\
& =2 \cdot C_{d} \cdot C_{v} \cdot A_{\text {orifice }} \cdot\left(P_{f u e l}-P_{\text {amb }}\right)
\end{aligned}
$$

where $C_{d}$ is the discharge coefficient, $C_{v}$ is the velocity coefficient, and $A_{\text {orifice }}$ is the orifice exit area. As seen in Equation 1 and 2, the mass injection rate $\left(\dot{m}_{f u e l}\right)$ and the injection velocity $\left(U_{f u e l}\right)$, which are the key injection related parameters, are coupled by the pressure drop across the orifice and the liquid fuel density. Thus, it is impossible to keep all of the injection parameters constant when the liquid density is perturbed, and only one of the parameters can be chosen to be the same as the baseline case.

To be consistent with spray experiments [11-13] where constant injection pressure is applied regardless of the liquid fuel density, the density perturbation in this study was made while maintaining the pressure drop across orifice $\left(P_{f u e l}-P_{a m b}\right)$. As a result, the fuel mass flow rate was proportional to $\rho_{\text {fuel }} 0.5$, and the injection velocity was proportional to $\rho_{\text {fuel }}{ }^{-0.5}$ for the density perturbation cases, as indicated by Equations 1 and 2. Also, a constant pressure drop resulted in constant jet momentum flow rate (Equation 3). This relationship has been experimentally validated by Genzale et al. [12] for sprays of regular diesel and higher density biodiesel at a constant injection pressure.

\section{Results - Liquid Penetration Length}

Figure 6 summarizes the relative change in the liquid penetration length for the physical property perturbations. While perturbations of density, vapor pressure, viscosity, and specific heat resulted in $\pm 4 \sim 10 \%$ changes in liquid penetration for the $900 \mathrm{~K}$ case and $\pm 5 \sim 18 \%$ changes for the $750 \mathrm{~K}$ case, surface tension and heat of vaporization perturbations caused a at most a $\pm 2 \%$ change in liquid penetration length. Although all six physical properties considered 


\section{UNCLASSIFIED}

in this study are included in one or more spray submodels (breakup model, evaporation model, etc.) as model parameters, this observation indicates that the impact of surface tension and heat of vaporization on the predicted liquid penetration length is considerably smaller than the other four properties under the conditions studied. When the sensitivity factor, which is defined as the $\%$ change in liquid penetration length over the \% change in physical property, is plotted as shown in Figure 7, liquid penetration length was most sensitive to density and specific heat for both conditions. Details on how these property perturbations affect liquid penetration are discussed in the following sections.

\subsection{Viscosity and Surface Tension Effects}

It has been shown that greater liquid fuel viscosity and surface tension slow the droplet breakup and atomization process $[41,42]$ which in turn contribute to longer liquid penetration lengths. From a modeling standpoint, both viscosity and surface tension play a significant role in spray breakup, as they determine the Reynolds and Weber numbers, which are key model parameters. The results in Figure 6 replicated the expected experimental trends - the liquid penetration length gets longer as viscosity and surface tension increase. However, the variation in surface tension over the relatively large range of hydrocarbon molecules considered in this study did not have a significant effect on liquid penetration length. The magnitudes of the surface tension and viscosity sensitivity factors shown in Figure 7 were not significantly different, which also confirms that the substantial difference in liquid penetration length shown in Figure 6 is caused by much larger variations in viscosity. The more significant effect of viscosity is consistent with previous experimental analysis [42], where viscosity, and not surface tension, was the dominating factor to changes in the Sauter Mean Diameter (SMD) of various liquid fuel sprays. SMD $\left(d_{32}\right)$, is defined as 


\section{UNCLASSIFIED}

$$
d_{32}=\sum_{i=1}^{N_{t o t}} d_{i}^{3} \sum_{i=1}^{N_{t o t}} d_{i}^{2}
$$

where $N_{\text {tot }}$ is the total number of drops and $d_{i}$ is the diameter of an individual droplet. SMD characterize the droplet size distribution within a spray with a single droplet with the same volume to surface ratio [7]. Figure 8 compares SMD of the viscosity and surface tension perturbation cases at $900 \mathrm{~K}, 22.8 \mathrm{~kg} / \mathrm{m}^{3}$, where it is illustrated that the SMD change in the viscosity perturbation was significantly greater than that within the surface tension perturbation. Thus, the effect of viscosity variations on the liquid breakup process and, consequently, the liquid penetration length, was much more important than that of surface tension.

\subsection{Specific Heat and Heat of Vaporization Effects}

Another physical factor influencing liquid penetration length is the total thermal energy required to heat up and vaporize liquid fuel, as experimentally shown in Siebers [10] and Higgins

et al. [11]. The correlation from these experiments implies that higher fuel specific heat and latent heat of vaporization result in longer liquid lengths. An energy balance for a single liquid droplet with a uniform temperature that vaporizes when heated by the ambient can be used to understand the importance of these properties:

$$
A_{d} q_{d}=C_{p, l i q} m_{d} \frac{d T_{d}}{d t}-\frac{d m_{d}}{d t} \Delta h_{v a p}
$$

where $A_{d}$ is the droplet surface area, $q_{d}$ is the heat flux from the ambient to the droplet, $T_{d}$ is the droplet temperature, $C_{p, l i q}$ is the specific heat of the fuel at $T_{d}, m_{d}$ is the droplet mass at $T_{d}$, and $\Delta h_{\text {vap }}$ is the heat of vaporization at $T_{d}$. Equation 5 implies that the heat transferred from the ambient to the liquid fuel is used either for increasing the liquid temperature or for causing the phase to change from liquid to vapor. Integrating Equation 5 over the lifetime of the evaporating 


\section{UNCLASSIFIED}

liquid droplet provides $Q_{\text {total }}$, the total heat transfer needed from the ambient to vaporize the liquid droplet:

$$
\begin{aligned}
& \int_{t_{\text {init }}}^{t_{\text {end }}} A_{d} q_{d} d t=\int_{T_{d, \text { init }}}^{T_{d, \text { end }}} C_{p, l i q} m_{d} d T_{d}-\int_{m_{d, \text { init }}}^{m_{d}=0} \Delta h_{v a p} d m_{d} \\
& Q_{\text {total }}=\int_{T_{d, \text { init }}}^{T_{d, \text { end }}}\left(C_{p, l i q} m_{d}-\Delta h_{\text {vap }} \frac{d m_{d}}{d T_{d}}\right) d T_{d}
\end{aligned}
$$

where $t_{\text {init }}, T_{d, \text { init }}$ and $m_{d \text {,init }}$ are the initial time, temperature, and mass of the droplet, and $t_{\text {end }}$ and $T_{d, e n d}$ are the final time and droplet temperature when the droplet mass reaches zero. Note $C_{p, l i q}$, $m_{d}$, and $\Delta h_{v a p}$ are all functions of the droplet temperature. Since $d m_{d} / d T_{d}$ is negative for a vaporizing droplet, it is clear from Equation 6 that higher specific heat and heat of vaporization will result in a greater amount of heat transfer from the ambient to vaporize the liquid fuel. As seen in Figure 6, the simulation results were consistent with this analysis and the experimental observations, where greater specific heat and heat of vaporization resulted in longer liquid penetration lengths.

However, contrary to the specific heat cases, varying the heat of vaporization caused only a very small change in liquid length. Not only was the relative change in liquid penetration length small, but the sensitivity factor for the heat of vaporization was significantly smaller than the specific heat, as shown in Figure 7. This is mainly due to the ambient pressures of the test conditions, which were much higher than the critical pressure of liquid n-dodecane. Note that while the vapor pressure of n-dodecane increases exponentially until it reaches its critical pressure of $1.8 \mathrm{MPa}$ at $658 \mathrm{~K}$, the ambient pressures were $\sim 6 \mathrm{MPa}$ for the $900 \mathrm{~K}$ case and $\sim 5$ $\mathrm{MPa}$ for the $750 \mathrm{~K}$ case, which are relevant to the TDC conditions in compression ignition engines [10]. Under such high pressures, the evaporation model used in the current study [29] predicts that the bulk of evaporation occurs at liquid temperatures close to the critical temperature where the vapor pressure is the highest, because the ratio between the vapor pressure of the liquid fuel and the ambient pressure $\left(p_{v a p} / p_{a m b}\right)$ is the key model parameter driving the 


\section{UNCLASSIFIED}

evaporation process. In other words, when the droplet temperature is not close to the critical temperature, $p_{v a p} / p_{a m b}$ is too small and causes a negligibly small amount of evaporation to occur. Figure 9 illustrates the fraction of evaporating mass within each liquid temperature bin (10 K) relative to the total evaporating mass at a given time $(0.2 \mathrm{~ms})$ for the $900 \mathrm{~K}, 22.8 \mathrm{~kg} / \mathrm{m}^{3}$ case, and clearly shows that the bulk of the phase change occurred at droplet temperatures over $600 \mathrm{~K}$, which is in proximity to the critical temperature. $C_{p, l i q}$ increases with liquid temperature, however $\Delta h_{v a p}$ decreases and eventually becomes zero at the critical temperature, as shown in Figure 10 for n-dodecane. Thus, when the liquid temperature approaches the critical temperature, the heat transfer needed for vaporization $\left(Q_{\text {total }}\right)$ in Equation 6 is dominated by $C_{p, l i q}$, with a much smaller contribution from $\Delta h_{\text {vap }}$. Therefore, in proximity to the critical temperature, the perturbation of the heat of vaporization has only a marginal effect on $Q_{\text {total }}$, resulting in a much smaller change in liquid penetration relative to the specific heat perturbations.

\subsection{Density Effects}

Increasing liquid fuel density has been shown to increase liquid penetration length in spray experiments $[8,11-13]$. The current simulation results in Figure 6 captured the expected trend, showing that the liquid penetration length is sensitive to liquid density variations. Also, the sensitivity factor of liquid length to fuel density was the highest among all the physical properties considered for both test conditions, as shown in Figure 7. This effect was a result of the entrainment rate, which is defined as the ratio of entrained ambient mass to the fueling rate, which is inversely proportional to the square root of the fuel density as analyzed in $[8,12,13]$. Thus, a higher liquid density requires the entrainment of additional ambient air, which demands more mixing time or a greater mixing length to complete the vaporization process. 


\section{UNCLASSIFIED}

\subsection{Vapor Pressure Effects}

Vapor pressure, a measure of liquid volatility, is a well-known fuel property that affects liquid penetration $[10,11,13]$ by influencing the vaporization process. Higher vapor pressure enhances liquid fuel vaporization, resulting in shorter liquid penetration, which was well captured by the current model as shown in Figure 6 and Figure 7. An interesting observation is that the effect of vapor pressure was much more significant in the lower temperature case. Figure 6 shows that the same perturbations in vapor pressure resulted in a $4 \sim 6 \%$ relative change in the $900 \mathrm{~K}$ case, but in a $13 \sim 18 \%$ change in the $750 \mathrm{~K}$ case. Because of the faster heat transfer to the liquid fuel for the higher ambient temperature case, the effect of fuel vapor pressure on liquid penetration is less pronounced in the $900 \mathrm{~K}$ case.

\section{Results - Ignition Delay Time}

To better understand the effect of the liquid fuel properties on the spray ignition characteristics under the simulated conditions, the calculated global heat release rates for the baseline cases are shown in Figure 11 (a) at $900 \mathrm{~K}, 22.8 \mathrm{~kg} / \mathrm{m}^{3}$ and (b) at $750 \mathrm{~K}, 22.8 \mathrm{~kg} / \mathrm{m}^{3}$. Two-stage ignition is predicted for both cases, including low temperature heat release (LTHR), negative temperature coefficient (NTC) behavior, and high temperature ignition chemistry. The LTHR phase in Figure 11 is defined as the period between the start of heat release and the first heat release rate peak, while the NTC period is defined as the time from the first heat release rate peak to the start of high temperature ignition, which is defined as the time when the maximum rise rate of peak temperature occurs [22]. The ignition process takes much longer for the $750 \mathrm{~K}$ case, primarily due to the longer duration of the LTHR and NTC phases of ignition.

Figure 12 shows the time evolution of the local temperatures during the ignition process

for the $900 \mathrm{~K}, 22.8 \mathrm{~kg} / \mathrm{m}^{3}$ case. In the temperature contours at $0.37 \mathrm{~ms}$ and $0.41 \mathrm{~ms}$ after the start of injection, the temperature rise is observed at the periphery of the spray where the equivalence ratio is $1 \sim 2$. A similar initial temperature rise at the spray periphery was predicted in the work of 


\section{UNCLASSIFIED}

Som and Aggarwal [43]. At $0.45 \mathrm{~ms}$, high temperature chemistry, which leads to the ignition of the fuel spray, is about to start in the interior of the spray where the fuel/air mixture is slightly rich and local temperature is the highest. A similar ignition process was predicted for the $750 \mathrm{~K}$ case (not shown), with the initial heat release at the periphery of the spray and the onset of high temperature heat release in the spray interior.

The two stage ignition process within the n-dodecane spray can be better understood when the time evolution of local reactivity is determined during the ignition delay period, as shown in Figure 13. The local reactivity was calculated using a methodology similar to the one shown in Kodavasal et al. [44]. In this case, the local reactivity was represented by the inverse of the ignition delay time calculated from constant volume homogeneous reactor simulations initialized with the local temperature, pressure, and gas phase composition at a given instance of time in each cell of the fuel spray. These ignition delay calculations were performed using the zero dimensional chemistry solver included in the CFD package CONVERGE [24] with the same chemical mechanism as the CFD simulations. A shorter ignition delay time is indicative of higher mixture reactivity, hence the inverse of the calculated ignition delay time can be used to gauge local reactivity and the preferential ignition sites within the spray. Figure 13 illustrates the local reactivity distribution during the ignition delay period for the $900 \mathrm{~K}, 22.8 \mathrm{~kg} / \mathrm{m}^{3}$ case. During the LTHR phase $(0.33 \mathrm{~ms} \sim 0.39 \mathrm{~ms})$, it can be seen that the most reactive charge is located at the periphery of the spray where the temperature is greater than that of the jet interior and the equivalence ratio is near stoichiometric or slightly rich, which is in agreement with the location of the initial temperature rise observed in Figure 12. As time progresses (from $0.41 \mathrm{~ms}$ $0.43 \mathrm{~ms}$ ), ignition process enters the NTC regime and approaches high temperature ignition - the regions of peak reactivity gradually shift into the interior of the spray as a result of heat and mass transfer, where high temperature ignition eventually occurs.

Figure 14 summarizes the relative changes in ignition delay time with physical property perturbations for the (a) $900 \mathrm{~K}, 22.8 \mathrm{~kg} / \mathrm{m}^{3}$ case and (b) $750 \mathrm{~K}, 22.8 \mathrm{~kg} / \mathrm{m}^{3}$ case. For both conditions, the perturbations of specific heat and density have significant impact on the 


\section{UNCLASSIFIED}

calculated ignition delay $(-10 \% \sim 9 \%$ for specific heat, $-7 \% \sim 7 \%$ for density); vapor pressure and the latent heat of vaporization have a small effect $(-2 \% \sim 1 \%)$, while variations in viscosity and surface tension marginally affect ignition delay (less than $0.5 \%$ at most). No meaningful deviations from the baseline cases could be observed for the viscosity and surface tension cases when local temperatures and equivalence ratio within the spray are compared, despite their effect on liquid length. On the other hand, the ignition delay time is much more sensitive to perturbations in specific heat and density than rest of the properties, which is also clearly seen in the sensitivity factors plotted in Figure 15. The reason for these behaviors is discussed in the following sections.

\subsection{Specific Heat Effects}

Figure 16 shows the calculated global heat release rates for the specific heat perturbation cases. For both test conditions, the specific heat perturbation had the largest impact on the calculated ignition delay, causing a $-10 \%$ to $\sim 9 \%$ deviation from the baseline cases. The entire ignition process from the start of low temperature heat release to the transition to high temperature chemistry was slowest for the perturbation with the greatest specific heat.

To understand this behavior's root cause, reactivity contours for n-dodecane/air mixtures were calculated for each test condition just prior to heat release in the equivalence ratio temperature domain as shown in Figure 17; markers noting the $\Phi$ and $T$ in each cell are plotted onto the contours. For both cases, it is clear that the local temperatures decrease with an increase in specific heat at a given equivalence ratio. This local temperature difference is caused by the change in the amount of heat that should be transferred from the ambient charge to the liquid fuel for its vaporization $\left(Q_{\text {total }}\right.$ in Equation 6) as a result of the liquid specific heat perturbation. With a higher specific heat, a larger increase in liquid sensible internal energy is required for a given liquid fuel temperature increase - this causes the lower local mixture temperature at a given time. These local temperature variations influence the local reactivity, where from the reactivity 


\section{UNCLASSIFIED}

contour it is evident that the higher fuel specific heat case is colder and less reactive overall, resulting in a longer ignition delay.

Deviations in the ignition delay time caused by the specific heat perturbations, especially for the $750 \mathrm{~K}$ case, are $\pm \sim 0.2 \mathrm{~ms}$, which is equivalent to $\pm \sim 2.4$ crank angle degree at $2000 \mathrm{rpm}$. Such a change in ignition delay time or combustion phasing will have an effect on engine performance. Thus, emulating the specific heat of the liquid fuel should be considered for surrogates intended for spray/compression ignited combustion.

\subsection{Density Effects}

Figure 18 shows the calculated global heat release rates for the density perturbation cases. Density affects the ignition delay time, showing up to a $7 \%$ deviation from the baseline case for the perturbations shown in Figure 14. An important observation is that high temperature ignition is retarded for the higher density $900 \mathrm{~K}$ case $(3.6 \%$ increase in ignition delay), while ignition is advanced with higher density for the $750 \mathrm{~K}$ one $(7.1 \%$ decrease in ignition delay). Although the overall change in ignition delay time was not consistent, a common trend for each ignition event was slower LTHR progress and shorter NTC duration with greater liquid density. One of the major reasons for these variations was the change in air/fuel mixing resulting from the density variations. In the following sections, the influence of liquid fuel density on air/fuel mixing and ignition behavior are investigated.

\subsubsection{Liquid Density Effect on Turbulent Mixing}

As discussed previously, the injection velocity $\left(U_{f u e l}\right)$ and the mass injection rate $\left(\dot{m}_{f u e l}\right)$ were changed as a result of the density perturbation while maintaining the injection momentum flow rate $\left(\dot{m}_{f u e l} U_{f u e l}\right)$ and injection pressure. Since fuel injection is the driving force for turbulent

mixing within the initially quiescent spray chamber, the change in fuel injection related parameters such as $U_{f u e l}$ and $\dot{m}_{f u e l}$ impacts turbulent mixing rates. The changes in mixing rates for 


\section{UNCLASSIFIED}

the density perturbation cases are evident in the turbulent transport coefficients used within the RANS turbulence model of the current CFD simulations. Here, the turbulent diffusion of heat and mass are governed by the turbulent thermal diffusivity $\left(K_{t}\right)$ and turbulent mass diffusivity $\left(D_{t}\right)$ obtained from turbulent viscosity $\left(\mu_{t}\right)$ and turbulent Prandtl $(P r)$ and Schmidt $(S c)$ numbers:

$$
\begin{gathered}
K_{t}=K+c_{p} \frac{\mu_{t}}{\operatorname{Pr}_{t}} \\
D_{t}=\frac{\mu_{t}}{\rho S c_{t}}
\end{gathered}
$$

where $K$ is the molecular thermal conductivity, $c_{p}$ is the gaseous specific heat, $\operatorname{Pr}_{t}$ is the turbulent Prandtl number, and $S c_{t}$ is the turbulent Schmidt number. The turbulent viscosity calculated with the RANS model determines the turbulent diffusion of momentum. $K_{t}$ required for modeling turbulent heat transport and $D_{t}$ needed for turbulent species transport are calculated with the turbulent viscosity and with $\operatorname{Pr}_{t}$ and $S c_{t}$, respectively. Figure 19 (a) compares the turbulent mass diffusivities of the density perturbations for the $900 \mathrm{~K}$ case at $0.25 \mathrm{~ms}$ and clearly shows that $D_{t}$ is inversely proportional to the liquid fuel density. Since the turbulent component of thermal diffusivity is calculated in a similar manner to mass diffusivity, an identical trend was observed higher liquid density results in lower thermal diffusivity and slower rates of heat transfer. Thus, the turbulent transport of heat and species should be slower for the higher fuel density case. In Figure 19 (b), the turbulent thermal and mass transport rates of the baseline case are adjusted by changing the turbulent $P r_{t}$ and $S c_{t}$ numbers. As indicated by Equation 7 and 8 , higher $\operatorname{Pr}$ and $S c$ numbers reduce the rate of turbulent thermal and mass transport. As shown in Figure 19 (a) and (b), these mixing perturbations and liquid density perturbations have a similar effect on the turbulent mass diffusivities, indicating that the different effects have a similar impact on mixing rates.

Although the momentum flow rate of the fuel injection was kept constant for these density perturbations, notable change in turbulent mixing was still observed as shown in Figure 19 (a), which implies that an injection parameter other than $\dot{m}_{f u e l} U_{f u e l}$ caused such a deviation. To 


\section{UNCLASSIFIED}

identify which injection parameter change caused this difference, three other density perturbations were performed (identical density perturbation range) with different parameters kept constant, which were the mass injection rate $\left(\dot{m}_{f u e l}\right)$, the injection velocity $\left(U_{f u e l}\right)$, and the kinetic energy flow rate from the fuel injection event $\left(\dot{m}_{f u e l} U_{f u e l}{ }^{2}\right)$. The relationship between these parameters and the liquid density depends on the density perturbation method as summarized in Table 3. For example, when the liquid density is perturbed while maintaining the kinetic energy flow rate from the fuel injection event of the baseline case, the momentum flowrate $\left(\dot{m}_{f u e l} \cdot U_{f u e l}\right)$, the mass injection rate $\left(\dot{m}_{f u e l}\right)$, and the injection velocity $\left(U_{f u e l}\right)$ were proportional to $\rho^{1 / 3}, \rho^{2 / 3}$, and $\rho^{-1 / 3}$, respectively.

Figure 20 compares the local turbulent viscosities of four different density perturbations for the $900 \mathrm{~K}$ case at $0.25 \mathrm{~ms}$ after fuel injection. As indicated by Equation 7 and 8, turbulent viscosity determines the turbulent thermal and mass transport. Of all the density perturbation methods investigated, the case that maintained the injection velocity of the baseline case (Figure 20 (c)) showed the smallest deviation from the baseline case in turbulent viscosity. Also, the level of deviations for all four methods correlates with the change in injection velocity as a result of density perturbation. Based upon the relationship shown in Table 3, the change in the injection velocity from the baseline case is in the order of the case with constant injection mass $\left(U_{f u e l} \approx \rho^{-1}\right)$, constant momentum $\left(U_{\text {fuel }} \approx \rho^{-}{ }^{0.5}\right)$, constant kinetic energy $\left(U_{f u e l} \approx \rho^{-1 / 3}\right)$, and finally constant injection velocity ( $U_{\text {fuel }} \approx$ constant), which is in the same order to the deviations in the turbulent viscosities as shown in Figure 20. As a result, the global heat release rates of the density perturbations with constant injection velocity, especially during the first stage LTHR period, were the closest to the baseline case among the tested density perturbation methods as shown in Figure 21. Note the global heat release rates during LTHR phase $(0.25 \mathrm{~ms} \sim 0.4 \mathrm{~ms}$ for the $900 \mathrm{~K}$ case in Figure 21 (a), $1 \mathrm{~ms} \sim 1.4 \mathrm{~ms}$ for the $750 \mathrm{~K}$ case in Figure 21 (b)) were virtually identical to the baseline cases. Also, the timing of the first peak of the heat release rate (or the end of the LTHR) did not shift as much as the density perturbations with constant injection momentum (Figure 18). The difference in the magnitude of heat release rate at the end of LTHR and during 


\section{UNCLASSIFIED}

NTC period in Figure 21 may be attributed to the difference in the injected fuel mass, which was proportional to the liquid density. Such an effect is more obvious in the $750 \mathrm{~K}$ case in Figure 21 (b), where higher heat release rate due to increased injected fuel mass resulted in earlier onset of high temperature chemistry leading to shorter NTC duration.

From this analysis, it can be concluded that the major reason for the change in turbulent mixing rate as a result of liquid density perturbations with constant momentum flow rate (density perturbations in Figure 18) was the change in the injection velocity. Higher density reduces the injection velocity $\left(U_{\text {fuel }} \approx \rho_{-}{ }^{0.5}\right.$ ), which results in slower turbulent mixing rates. This conclusion is consistent with the analytic turbulent jet theoy [45]. For a free turbulent jet, theoretical analysis with the turbulent mixing length approach indicates that turbulent thermal and mass transport rates are proportional to the radial gradient of the mean velocity. Since the turbulence model used in this study (RNG k- $\varepsilon$ model) incorporates the same approach, the generation of turbulent kinetic energy. Consequently, the intensity of turbulent mixing depends on the radial gradient of the mean velocity. Thus, the higher liquid density with its slower injection velocity results in a smaller radial velocity gradient, which leads to slower turbulent mixing.

\subsubsection{Density Perturbation Effects on Mixing and LTHR}

To see the effects of liquid density on LTHR progress, the temperature-equivalence ratio distributions just before the start of heat release are shown in Figure 22 for the density perturbation with constant injection momentum. Unlike the specific heat perturbations, which showed three distinct bands clustered in the $T$ and $\Phi$ domain of Figure 17, there were no such large deviations in the $T-\Phi$ distributions of the density perturbations, as the bands approximately overlapped. Thus, the reactivity of the spray before LTHR cannot be compared solely based upon the $T-\Phi$ distribution.

Alternatively, using the method shown in [44], the mass distributions in the local reactivity dimension can be used to distinguish the differences in overall charge reactivity. 


\section{UNCLASSIFIED}

Taking the local pressure, temperature and composition from the sprays in Figure 22, the local reactivity of the density perturbation with constant injection momentum was calculated with the same method used for Figure 13. Figure 23 illustrates the mass distribution in the local reactivity space before the start of LTHR. The $900 \mathrm{~K}$ case as shown in Figure 23 (a) indicates that the spray with higher liquid fuel density has less mass in the most reactive regime relative to the baseline case. This trend is more obvious for the $750 \mathrm{~K}$ case in Figure 23 (b), where the mixing effect is more pronounced due to the much longer ignition delay period. This reactivity distribution indicates that while the $T$ - $\Phi$ distributions were overlapped to the baseline case as in Figure 17, the cell markers are for higher density case are less densely populated at the region where reactivity is the highest ( $\Phi$ of $1 \sim 1.5$ for the $900 \mathrm{~K}$ case, $\Phi$ of $\sim 1$ for the $750 \mathrm{~K}$ case). Thus, the slower turbulent mixing for the higher density case prepares the charge more slowly, creating a smaller mass of high reactivity mixture, which results in the slower LTHR reaction rates at a given time during the LTHR regime within Figure 18. Such an effect of the turbulent mixing rate on reactivity distribution before the start of LTHR is also observed in Figure 24, where the reactivity distributions of the density perturbations with constant injection velocity are shown. Since the change in turbulent mixing was the smallest when the injection velocity was kept constant as shown in Figure 20, the deviations in reactivity distribution was much smaller than the density perturbation with injection momentum constant as shown in Figure 23, in particular in the highest reactivity region. Thus, it confirms that the change in turbulent mixing was the key factor for the change in the progress of LTHR.

\subsubsection{Density Perturbation Effects on Mixing and NTC Duration}

Despite the slower LTHR progress, the NTC duration becomes shorter for the higher density case as shown in Figure 18. This behavior can be better understood through a numerical experiment where the turbulent thermal and mass diffusivities of the baseline case are artificially perturbed during the NTC period to isolate the effect of mixing on the NTC duration. Figure 25 


\section{UNCLASSIFIED}

compares the global heat release rate and peak temperature evolution of the $750 \mathrm{~K}$ case when the turbulent thermal and mass transport coefficients are perturbed at the start of the NTC period, indicated by the "perturbation start" line in the figure. The ranges of the $P r_{t}$ and $S c_{t}$ perturbations (x $0.9 \sim 1.1$ ) reflect the change in turbulent thermal and mass diffusivity predicted for the density perturbation cases shown in Figure 19 (b). While the heat release rate profile is virtually unchanged until $1.8 \mathrm{~ms}$ in Figure 25 (a), it is evident that the local peak temperatures begin to diverge in Figure 25 (b) starting at $1.6 \mathrm{~ms}$, with the slower mixing cases (higher $P r_{t}$ and $S c_{t}$ ) achieving significantly higher peak temperatures and heat release rate at a given time. The $T-\Phi$ distributions during the NTC period (at $1.8 \mathrm{~ms}$ ) are shown in Figure 26, where the slower mixing case $(S c, \operatorname{Pr} \times 1.1)$ achieves a $\sim 30 \mathrm{~K}$ higher peak temperature than the faster mixing $(S c, \operatorname{Pr} \times 0.9)$ case. Since the cumulative heat release at $1.8 \mathrm{~ms}$ is very similar for both cases (see Figure 25 (a)), the local temperature difference is caused in part by the change in the rate of turbulent transport, where the slower mixing case reduces mixing rates with the colder surroundings, resulting in higher local temperature. Such an effect leads to the earlier onset of high temperature chemistry and is a prime reason for the shorter NTC durations with higher density. An identical trend was observed for the $900 \mathrm{~K}$ case when the turbulent mixing was perturbed during the NTC period (not shown).

As shown above, the liquid density perturbations with constant injection momentum influenced turbulent mixing rates, which have competing effects on LTHR progress and NTC duration. Greater density makes the LTHR phase longer because it shifts $T$ - $\Phi$ distributions to favor lower reactivities, however the NTC duration is shorter with higher density, given that slower turbulent mixing rates allow peak temperatures to remain elevated during NTC. These effects are consistent for the $900 \mathrm{~K}$ and $750 \mathrm{~K}$ cases, as shown in Figure 27, which summarizes the deviations in LTHR peak timing (corresponding to the start of NTC) and NTC duration from the baseline case. Since the contribution of these two competing effects to the total ignition delay time measured by the onset of high temperature ignition changes drastically, the effect of fuel liquid density on ignition delay reverses when transitioning from $900 \mathrm{~K}$ to $750 \mathrm{~K}$. As seen in 


\section{UNCLASSIFIED}

Figure 27, the contribution from the deviations in LTHR progress is greater than that of NTC during the NTC duration for the $900 \mathrm{~K}$ case, while the change in NTC duration dominates the overall ignition delay change for the $750 \mathrm{~K}$ case. For this reason, the density effect on ignition delay could either increase or decrease the total ignition delay of the $900 \mathrm{~K}$ and $750 \mathrm{~K}$ cases.

\section{Summary and Conclusions}

CFD spray simulations were conducted to evaluate the effects of liquid fuel properties on liquid penetration length and ignition delay during compression ignited combustion. The perturbation of the liquid fuel physical properties was made to reflect the property ranges expected from hydrocarbon molecules that are frequently used in petroleum-derived diesel and jet fuel surrogates. The following conclusions can be drawn from the current study:

1. Among the six physical properties considered in this study, density, viscosity, vapor pressure and specific heat had a significant impact on the liquid penetration length (from $4 \%$ to $\sim 18 \%$ ). The impact of surface tension and heat of vaporization on liquid penetration length were minimal.

2. Vapor penetration length was not significantly affected by any of the liquid physical property perturbations, which is consistent with experimental observations.

3. Under the simulated ambient conditions, ignition delay was very sensitive to perturbations in the liquid fuel's specific heat. $-30 \% \sim+20 \%$ change in liquid specific heat resulted in $-10 \%$ to $9 \%$ change in ignition delay time. A greater specific heat increased the energy required for fuel vaporization, resulting in lower mixture temperatures, a less reactive fuel spray and a longer ignition delay. This is an important finding since liquid specific heat has been often neglected as a target property during the development of surrogates for diesel/spray combustion.

4. Liquid density also had a significant effect on ignition delay time through its competing effects on LTHR and NTC duration. $-8 \% \sim+20 \%$ change in liquid density caused up to $7 \%$ 


\section{UNCLASSIFIED}

change in ignition delay. With higher density, LTHR progress was slower, but NTC duration was also shorter. The main cause of this behavior was the change in turbulent thermal and mass transport rates due to the effect of liquid density on injection velocity. When different density perturbation methods were investigated, the density perturbation cases with constant injection velocity resulted in smallest deviations from the baseline case, in terms of the turbulent mixing rates and reactivity distribution before the start of initial heat release. This observation indicates the change in injection velocity was the reason for the change in turbulent mixing for the density perturbation cases. A lower mixing rate in the higher liquid density case was slower to form a reactive mixture for the LHTR, however during the NTC period, it was beneficial for the earlier onset of high temperature chemistry by allowing higher local temperatures. The relative contribution of these competing effects to the total ignition delay time changed depending on the ambient gas temperature, causing the importance of density to ignition delay to vary with ambient temperature.

5. Liquid fuel properties other than specific heat and density do not have significant impact on the ignition delay time.

6. Surrogates for spray/diesel combustion should consider emulating liquid density, specific heat, viscosity, and vapor pressure of the target fuel to properly capture the liquid penetration and ignition delay characteristics of the target fuel. When the target fuels and the surrogates are mixtures, for which vapor pressure cannot be defined, the distillation curve of the target fuel should be emulated since constituent vapor pressures govern the distillation curve behavior. 


\section{UNCLASSIFIED}

\section{Acknowledgements}

Funding for this work was provided by the Automotive Research Center (ARC), A U.S. Army Center of Excellence in the modeling and simulation of ground vehicles at the University of Michigan, with funding from government contract DoD-DoA W56HZV-04-2-0001 through the U.S. Army Tank Automotive Research, Development, and Engineering Center.

The authors wish to thank Dr. Daniel Lee of Convergent Science for his technical assistance and for the provision of the CONVERGE CFD code used in this work. The authors also gratefully acknowledge the assistance of Dr. Peter Kelly Senecal of Convergent Science and Dr. Sibendu Som of Argonne National Laboratory for their technical assistance with the CFD simulations.

\section{Disclaimer}

Reference herein to any specific commercial company, product, process, or service by trade name, trademark, manufacturer, or otherwise, does not necessarily constitute or imply its endorsement, recommendation, or favoring by the United States Government or the Department of Army (DoA). The opinions of the authors expressed herein do not necessarily state or reflect those of the United States Government or the DoA, and shall not be used for advertising or product endorsement purposes. 


\section{UNCLASSIFIED}

\section{References}

[1] Kim D, Martz J, Violi A. A surrogate for emulating the physical and chemical properties of conventional jet fuel. Combust Flame 2014;161:1489-98. doi:10.1016/j.combustflame.2013.12.015.

[2] Dooley S, Won SH, Chaos M, Heyne J, Ju Y, Dryer FL, et al. A jet fuel surrogate formulated by real fuel properties. Combust Flame 2010;157:2333-9. doi:10.1016/j.combustflame.2010.07.001.

[3] Dooley S, Won SH, Heyne J, Farouk TI, Ju Y, Dryer FL, et al. The experimental evaluation of a methodology for surrogate fuel formulation to emulate gas phase combustion kinetic phenomena. Combust Flame 2012;159:1444-66. doi:10.1016/j.combustflame.2011.11.002.

[4] Huber ML, Lemmon EW, Bruno TJ. Surrogate Mixture Models for the Thermophysical Properties of Aviation Fuel Jet-A. Energy Fuels 2010;24:3565-71. doi:10.1021/ef100208c.

[5] Naik CV, Puduppakkam KV, Modak A, Meeks E, Wang YL, Feng Q, et al. Detailed chemical kinetic mechanism for surrogates of alternative jet fuels. Combust Flame 2011;158:434-45. doi:10.1016/j.combustflame.2010.09.016.

[6] Violi A, Yan S, Eddings EG, Sarofim AF, Granata S, Faravelli T, et al. Experimental formulation and kinetic model for JP-8 surrogate mixtures. Combust Sci Technol 2002;174:399-417. doi:10.1080/00102200215080.

[7] Stiesch G. Modeling engine spray and combustion processes. Berlin; New York: Springer; 2003.

[8] Naber J, Siebers DL. Effects of Gas Density and Vaporization on Penetration and Dispersion of Diesel Sprays. SAE 9600341996.

[9] Siebers DL. Liquid-Phase Fuel Penetration in Diesel Sprays. SAE 9808091998.

[10] Siebers DL. Scaling Liquid-Phase Fuel Penetration in Diesel Sprays Based on MixingLimited Vaporization. SAE 1999-01-0528 1999.

[11] Higgins BS, Mueller CJ, Siebers DL. Measurements of Fuel Effects on Liquid-Phase Penetration in DI Sprays. SAE 1999-01-0519 1999.

[12] Genzale CL, Pickett LM, Kook S. Liquid Penetration of Diesel and Biodiesel Sprays at Late-Cycle Post-Injection Conditions. SAE 2010-01-0610 2010.

[13] Kook S, Pickett LM. Liquid length and vapor penetration of conventional, FischerTropsch, coal-derived, and surrogate fuel sprays at high-temperature and high-pressure ambient conditions. Fuel 2012;93:539-48. doi:10.1016/j.fuel.2011.10.004.

[14] Payri R, García-Oliver JM, Bardi M, Manin J. Fuel temperature influence on diesel sprays in inert and reacting conditions. Appl Therm Eng 2012;35:185-95. doi:10.1016/j.applthermaleng.2011.10.027.

[15] Wu Z, Zhu Z, Huang Z. An experimental study on the spray structure of oxygenated fuel using laser-based visualization and particle image velocimetry. Fuel 2006;85:1458-64. doi:10.1016/j.fuel.2005.12.024.

[16] Arcoumanis C, Bae C, Crookes R, Kinoshita E. The potential of di-methyl ether (DME) as an alternative fuel for compression-ignition engines: A review. Fuel 2008;87:1014-30. doi:10.1016/j.fuel.2007.06.007.

[17] Basha SA, Gopal KR, Jebaraj S. A review on biodiesel production, combustion, emissions and performance. Renew Sustain Energy Rev 2009;13:1628-34. doi:10.1016/j.rser.2008.09.031. 


\section{UNCLASSIFIED}

[18] Yu J, Bae C. Dimethyl ether (DME) spray characteristics in a common-rail fuel injection system. J Automob Eng 2003;217:1135-44. doi:10.1243/09544070360729473.

[19] Kim HJ, Park SH, Lee CS. A study on the macroscopic spray behavior and atomization characteristics of biodiesel and dimethyl ether sprays under increased ambient pressure. Fuel Process Technol 2010;91:354-63. doi:10.1016/j.fuproc.2009.11.007.

[20] Salvi AA, Assanis D, Filipi Z. Impact of Physical and Chemical Properties of Alternative Fuels on Combustion, Gaseous Emissions, and Particulate Matter during Steady and Transient Engine Operation. Energy Fuels 2012;26:4231-41. doi:10.1021/ef300531r.

[21] Som S, Longman DE, Ramírez AI, Aggarwal SK. A comparison of injector flow and spray characteristics of biodiesel with petrodiesel. Fuel 2010;89:4014-24. doi:10.1016/j.fuel.2010.05.004.

[22] Pei Y, Shan R, Som S, Lu T, Longman D, Davis MJ. Global Sensitivity Analysis of a Diesel Engine Simulation with Multi-Target Functions. SAE 2014-01-1117 2014.

[23] Ra Y, Reitz RD, McFarlane J, Daw CS. Effects of Fuel Physical Properties on Diesel Engine Combustion using Diesel and Bio-diesel Fuels. SAE 2008-01-1379 2008.

[24] Richards KJ, Senecal PK, Pomraning E. CONVERGE (Version 2.1.0). Middleton, WI: Convergent Science Inc.; 2013.

[25] Reitz RD, Diwakar R. Structure of High-Pressure Fuel Sprays. SAE 8705981987. doi:10.4271/870598.

[26] Schmidt DP, Rutland CJ. A New Droplet Collision Algorithm. J Comput Phys 2000;164:62-80. doi:10.1006/jcph.2000.6568.

[27] Post SL, Abraham J. Modeling the outcome of drop-drop collisions in Diesel sprays. Int J Multiph Flow 2002;28:997-1019. doi:10.1016/S0301-9322(02)00007-1.

[28] Liu AB, Mather D, Reitz RD. Modeling the Effects of Drop Drag and Breakup on Fuel Sprays. SAE 9300721993.

[29] Amsden AA, O’Rourke PJ, Butler TD. KIVA-II: A Computer Program for Chemically Reactive Flows with Sprays. Los Alamos National Laboratory; 1989.

[30] Kim HJ, Suh HK, Park SH, Lee CS. An Experimental and Numerical Investigation of Atomization Characteristics of Biodiesel, Dimethyl Ether, and Biodiesel-Ethanol Blended Fuel. Energy Fuels 2008;22:2091-8. doi:10.1021/ef700692w.

[31] Luo Z, Plomer M, Lu T, Som S, Longman DE, Sarathy SM, et al. A reduced mechanism for biodiesel surrogates for compression ignition engine applications. Fuel 2012;99:143-53. doi:10.1016/j.fuel.2012.04.028.

[32] Som S, D'Errico G, Longman D, Lucchini T. Comparison and Standardization of Numerical Approaches for the Prediction of Non-reacting and Reacting Diesel Sprays. SAE 2012-01-1263 2012. doi:10.4271/2012-01-1263.

[33] Senecal PK, Pomraning E, Richards KJ, Som S. GRID-CONVERGENT SPRAY MODELS FOR INTERNAL COMBUSTION ENGINE CFD SIMULATION. ICEF2012-92043 2012.

[34] Dagaut P, Cathonnet M. The ignition, oxidation, and combustion of kerosene: A review of experimental and kinetic modeling. Prog Energy Combust Sci 2006;32:48-92. doi:10.1016/j.pecs.2005.10.003.

[35] Pitz WJ, Mueller CJ. Recent progress in the development of diesel surrogate fuels. Prog Energy Combust Sci 2011;37:330-50. doi:10.1016/j.pecs.2010.06.004.

[36] Design Institute for Physical Properties, Sponsored by AIChE. DIPPR Project 801 - Full Version. Design Institute for Physical Property Research/AIChE; 2012. 


\section{UNCLASSIFIED}

[37] Narayanaswamy K, Pepiot P, Pitsch H. A chemical mechanism for low to high temperature oxidation of n-dodecane as a component of transportation fuel surrogates. Combust Flame 2014;161:866-84. doi:10.1016/j.combustflame.2013.10.012.

[38] Sandia National Laboratories. Engine Combustion Network. Engine Combust Netw n.d. http://www.sandia.gov/ecn/index.php.

[39] Pickett LM, Manin J, Genzale CL, Siebers DL, Musculus MPB, Idicheria CA. Relationship Between Diesel Fuel Spray Vapor Penetration/Dispersion and Local Fuel Mixture Fraction. SAE 2011-04-12 2011.

[40] Lillo PM, Pickett LM, Persson H, Andersson O, Kook S. Diesel Spray Ignition Detection and Spatial/Temporal Correction. SAE 2012-01-1239 2012.

[41] Wilkinson PM, Van Schayk A, Spronken JPM, Van Dierendonck L.- The influence of gas density and liquid properties on bubble breakup. Chem Eng Sci 1993;48:1213-26. doi:10.1016/0009-2509(93)81003-E.

[42] Ejim CE, Fleck BA, Amirfazli A. Analytical study for atomization of biodiesels and their blends in a typical injector: Surface tension and viscosity effects. Fuel 2007;86:1534-44. doi:10.1016/j.fuel.2006.11.006.

[43] Som S, Aggarwal SK. Effects of primary breakup modeling on spray and combustion characteristics of compression ignition engines. Combust Flame 2010;157:1179-93. doi:10.1016/j.combustflame.2010.02.018.

[44] Kodavasal J, Lavoie GA, Assanis DN, Martz JB. The effects of thermal and compositional stratification on the ignition and duration of homogeneous charge compression ignition combustion. Combust Flame 2015;162:451-61. doi:10.1016/j.combustflame.2014.07.026.

[45] Abramovich GN. The theory of turbulent jets. Cambridge, Mass.: MIT Press; 1963. 


\section{UNCLASSIFIED}

\section{Tables}

Table 1. Details of experimental spray data from Sandia National Laboratories [38-40]

\begin{tabular}{|c|c|c|c|c|c|}
\hline \multirow[b]{2}{*}{ Ambient Temp. } & \multicolumn{2}{|l|}{ Non-reacting } & \multicolumn{3}{|l|}{ Reacting } \\
\hline & $900 \mathrm{~K}$ & $1100 \mathrm{~K}$ & $900 \mathrm{~K}$ & $1200 \mathrm{~K}$ & $750 \mathrm{~K}$ \\
\hline Ambient Density & $22.8 \mathrm{~kg} / \mathrm{m}^{3}$ & $15.2 \mathrm{~kg} / \mathrm{m}^{3}$ & $22.8 \mathrm{~kg} / \mathrm{m}^{3}$ & $22.8 \mathrm{~kg} / \mathrm{m}^{3}$ & $22.8 \mathrm{~kg} / \mathrm{m}^{3}$ \\
\hline Ambient Pressure & $6.1 \mathrm{MPa}$ & $5.0 \mathrm{MPa}$ & 6.1 MPa & 7.9 MPa & 4.9 $\mathrm{MPa}$ \\
\hline Ignition Delay $^{\mathrm{a}}$ & - & - & $0.398 \mathrm{~ms}$ & $0.147 \mathrm{~ms}$ & $1.723 \mathrm{~ms}$ \\
\hline Injection Duration & $<4 \mathrm{~ms}$ & $<4 \mathrm{~ms}$ & $1.5 \mathrm{~ms}$ & $1.5 \mathrm{~ms}$ & $2.5 \mathrm{~ms}$ \\
\hline $\begin{array}{l}\text { Ambient Composition } \\
\left(\mathrm{N}_{2} / \mathrm{CO}_{2} / \mathrm{H}_{2} \mathrm{O} / \mathrm{O}_{2} \text {, mole }\right. \\
\text { fraction) }\end{array}$ & \multicolumn{2}{|c|}{$0.8971 / 0.0652 / 0.0377 / 0$} & \multicolumn{3}{|c|}{$0.7515 / 0.0622 / 0.0362 / 0.15$} \\
\hline Fuel & \multicolumn{5}{|l|}{ n-dodecane } \\
\hline Fuel Temperature & \multicolumn{5}{|l|}{$373 \mathrm{~K}$} \\
\hline Injector & \multicolumn{5}{|c|}{ Spray A (Serial \# 210677), Common rail, Single hole, $90 \mu \mathrm{m}$ diameter } \\
\hline Injection Pressure & \multicolumn{5}{|l|}{$150 \mathrm{MPa}$} \\
\hline
\end{tabular}

${ }^{a}$ From the average of three optically measured ignition delays in [40].

Table 2. Multipliers assigned to baseline properties for their perturbations.

\begin{tabular}{lll} 
& Perturb Min & Perturb Max \\
\hline Density & 0.92 & 1.2 \\
Vapor Pressure & 0.41 & 10 \\
Viscosity & 0.4 & 2 \\
Surface Tension & 0.7 & 1.25 \\
Heat of Vaporization & 0.8 & 1.16 \\
Specific Heat Capacity & 0.7 & 1.2 \\
\hline
\end{tabular}




\section{UNCLASSIFIED}

Table 3. Effects of liquid fuel density on injection-related parameters for different density perturbation methods.

\begin{tabular}{llllll} 
Density perturbation & Controlled & \multicolumn{3}{l}{ Relationship with the liquid density } \\
\cline { 3 - 5 } methods & parameter & $\dot{m}_{f u e l} \cdot U_{f u e l}$ & $\dot{m}_{f u e l}$ & $U_{f u e l}$ & $\dot{m}_{f u e l} \cdot U_{f u e l}^{2}$ \\
\hline $\begin{array}{l}\text { Constant injection } \\
\text { momentum }\end{array}$ & $\dot{m}_{f u e l} \cdot U_{f u e l}$ & - & $\rho^{0.5}$ & $\rho^{-0.5}$ & $\rho^{-0.5}$ \\
$\begin{array}{l}\text { Constant injection mass } \\
\text { flow rate }\end{array}$ & $\dot{m}_{f u e l}$ & $\rho^{-1}$ & - & $\rho^{-1}$ & $\rho^{-2}$ \\
$\begin{array}{l}\text { Constant injection } \\
\text { velocity }\end{array}$ & $U_{f u e l}$ & $\rho$ & & & \\
$\begin{array}{l}\text { Constant injection } \\
\text { kinetic energy }\end{array}$ & $\dot{m}_{f u e l} \cdot U_{f u e l}^{2}$ & $\rho^{1 / 3}$ & $\rho^{2 / 3}$ & $\rho^{-1 / 3}$ & -
\end{tabular}




\section{UNCLASSIFIED}

\section{Figures}
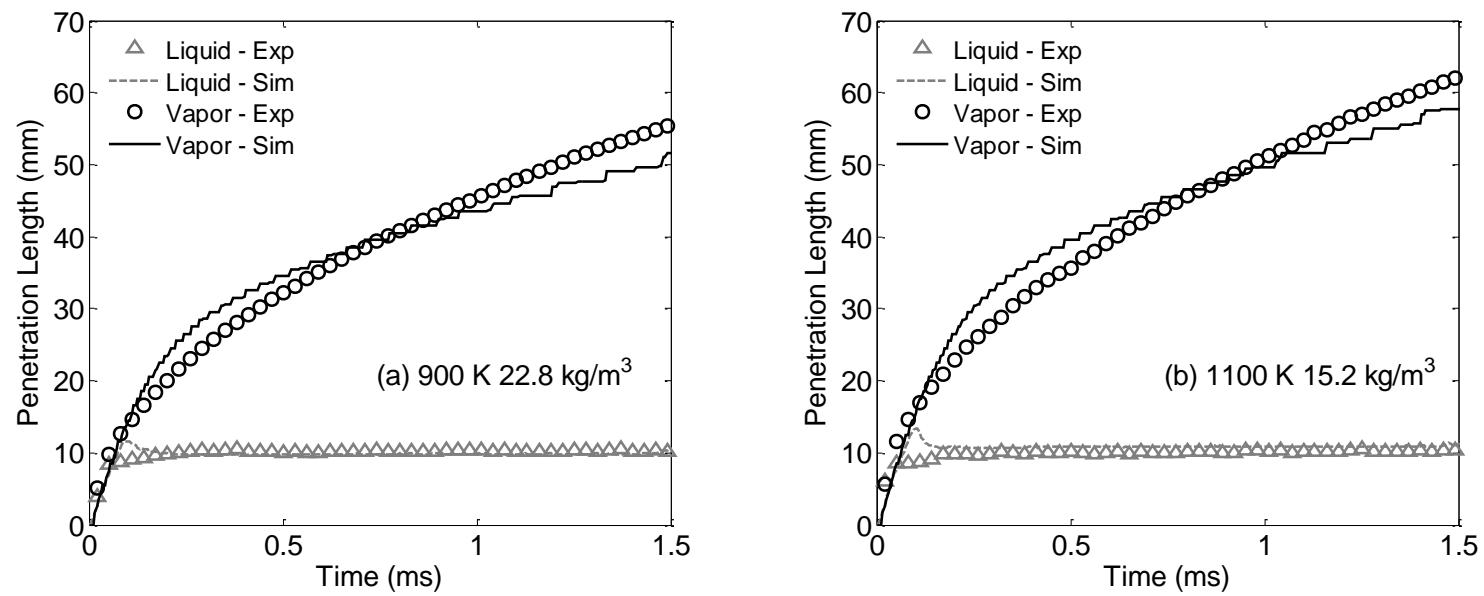

Figure 1. Comparison of predicted and experimental liquid/vapor penetration lengths.
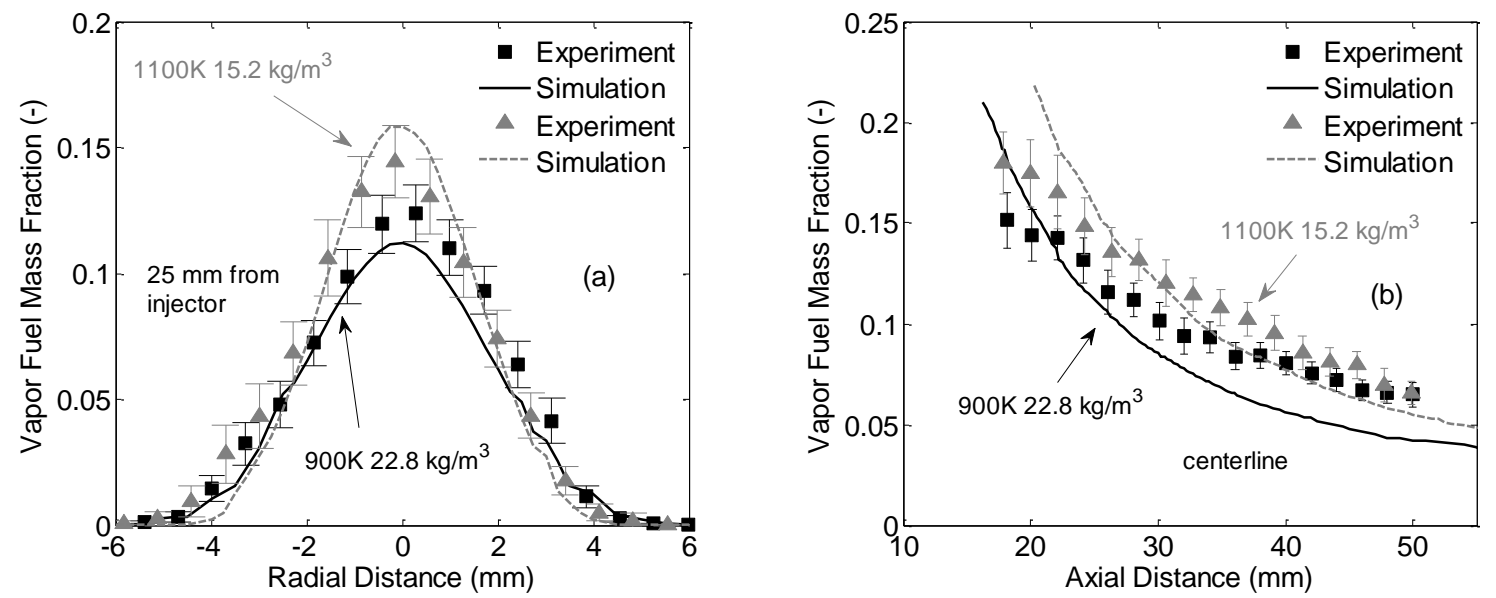

Figure 2. Comparison of predicted and experimental vapor fuel mass fraction [39] at (a) $25 \mathrm{~mm}$ downstream from the injector tip and (b) at the jet centerline. The steady-state experimental data is compared against the simulation results at $2.5 \mathrm{~ms}$ after the start of the injection, when the mixing fields shown in (a) and (b) are steady. 


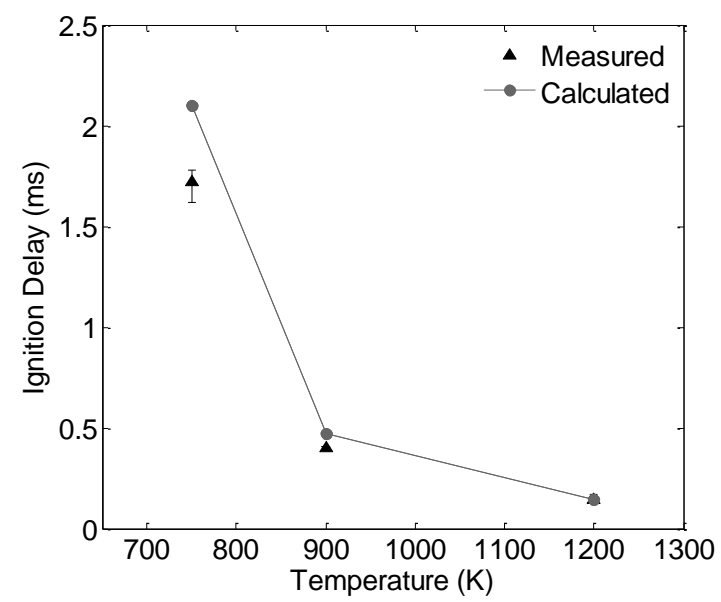

Figure 3. Comparison of measured and calculated ignition delays. Error bars show the minimum and maximum values from three experimental runs [40].

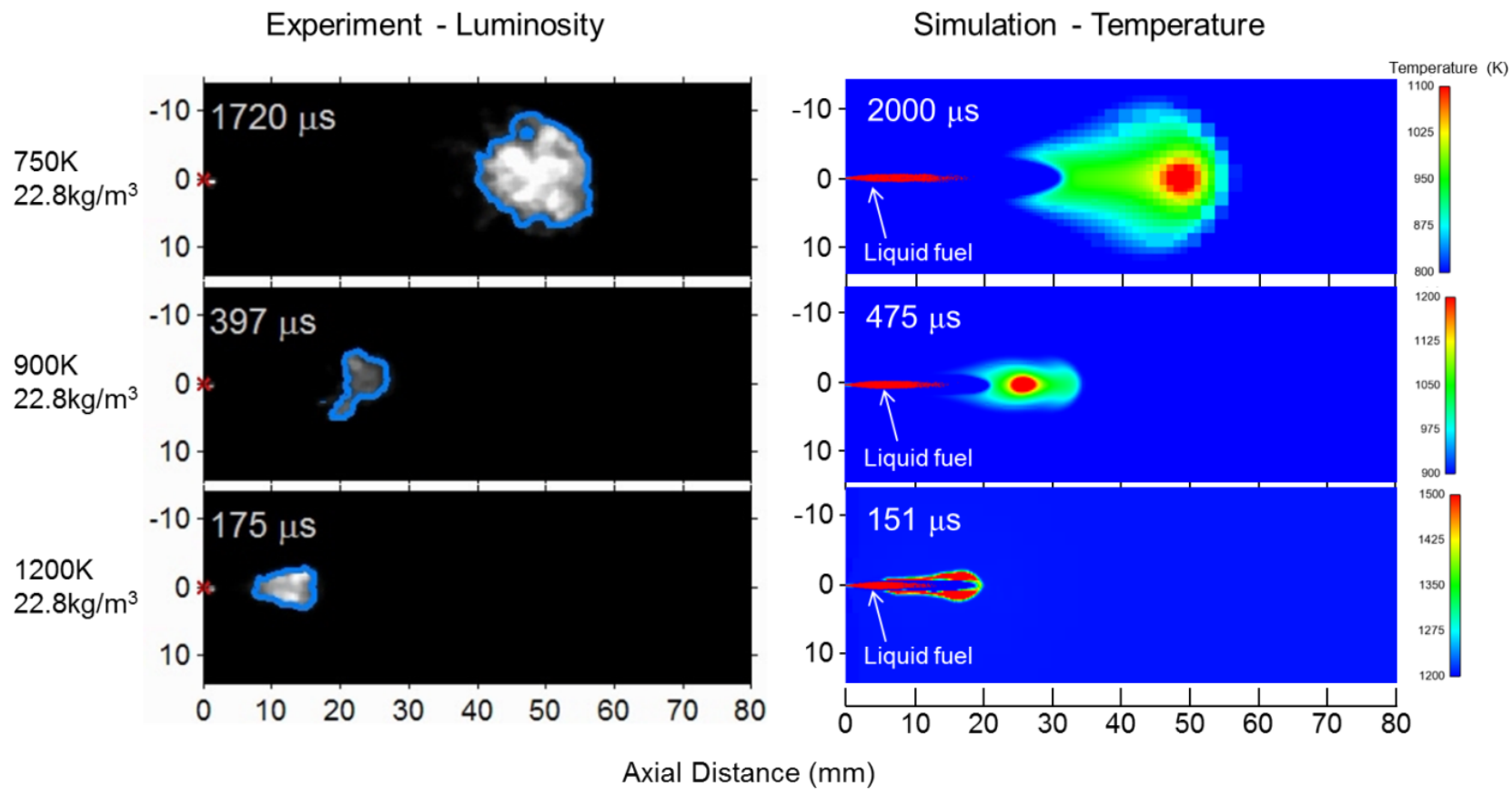

Figure 4. Comparison of high temperature chemiluminescence images from experiments [38] with the predicted local temperatures near the time of ignition for the reacting spray cases at a given time. Image times are noted for each case in the figure. 


\section{UNCLASSIFIED}

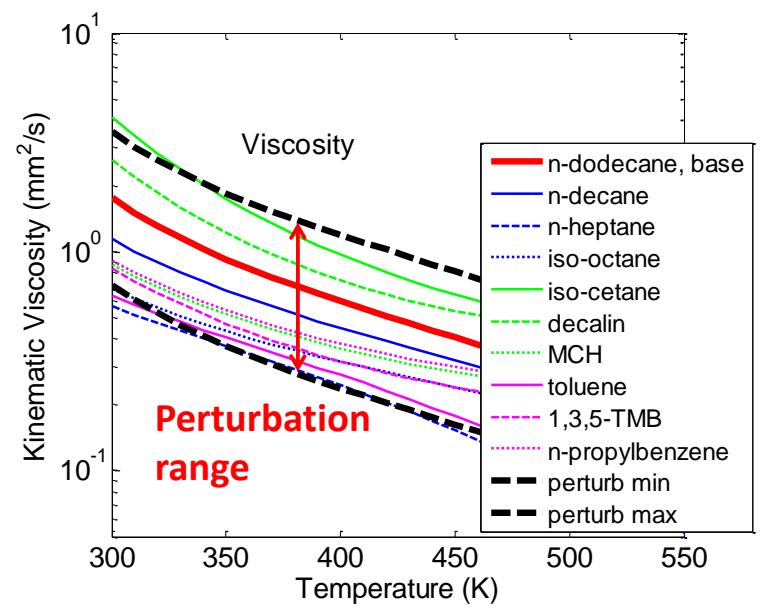

Figure 5. The methodology that was implemented for the perturbation of liquid fuel physical properties. The perturbation of viscosity is shown.
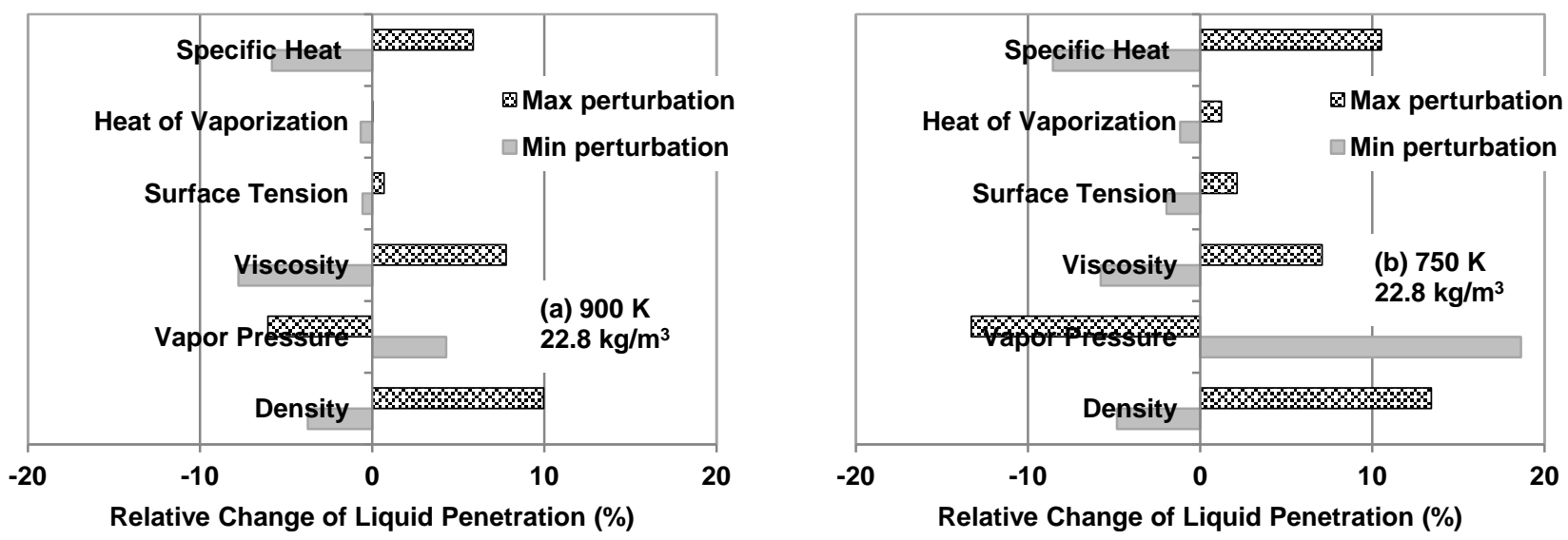

Figure 6. Relative change in liquid penetration length due to physical property perturbations at (a) $900 \mathrm{~K}, 22.8 \mathrm{~kg} / \mathrm{m}^{3}$ and (b) $750 \mathrm{~K}, 22.8 \mathrm{~kg} / \mathrm{m}^{3}$. The baseline liquid penetration length is $9.8 \mathrm{~mm}$ for (a) and $11.5 \mathrm{~mm}$ for (b). 


\section{UNCLASSIFIED}
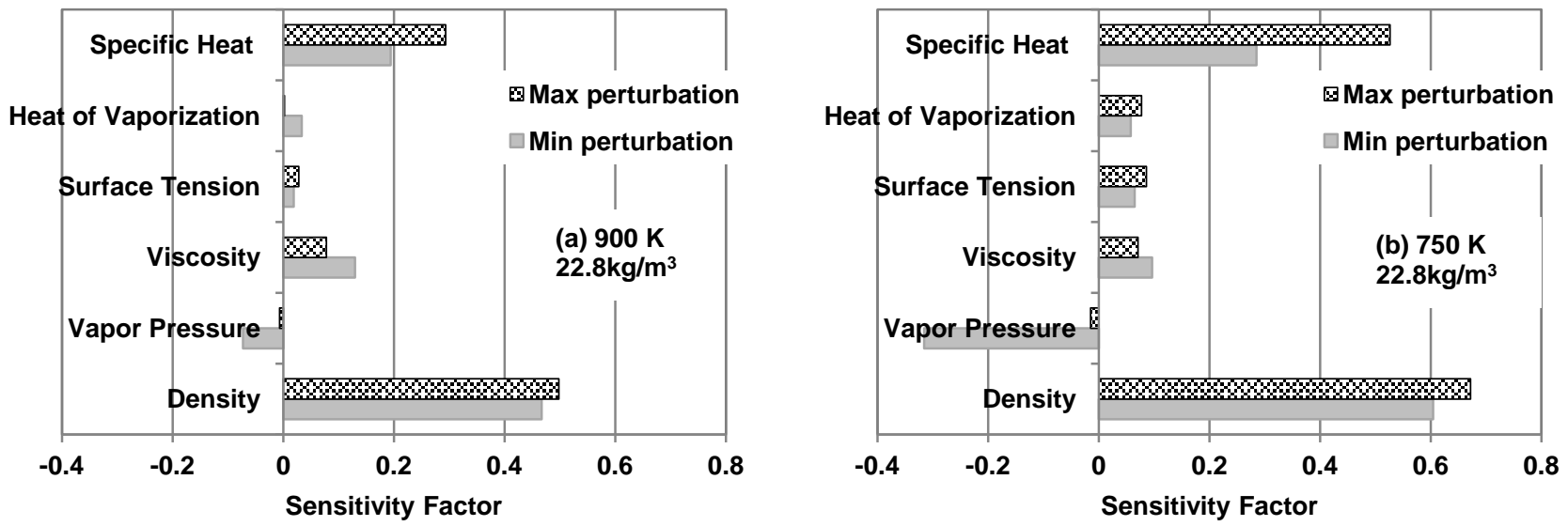

Figure 7. The sensitivity factor for liquid penetration length due to physical property perturbations at (a) $900, \mathrm{~K} 22.8 \mathrm{~kg} / \mathrm{m}^{3}$ and (b) $750, \mathrm{~K} 22.8 \mathrm{~kg} / \mathrm{m}^{3}$.

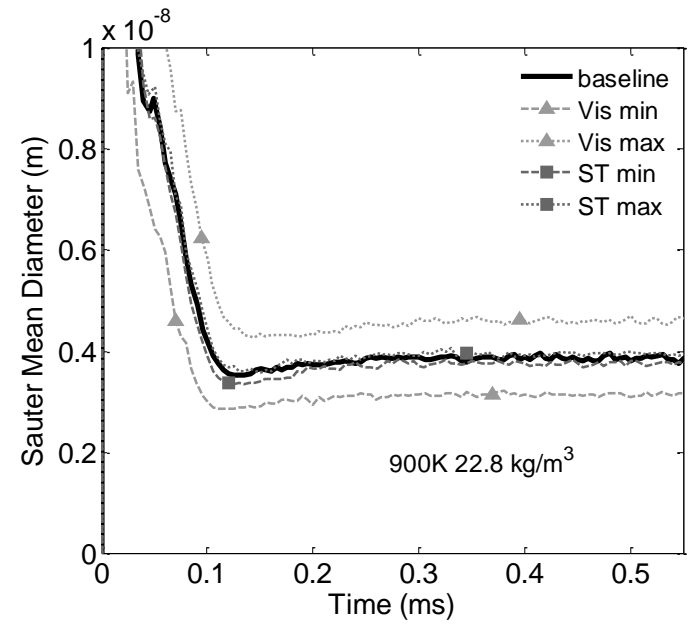

Figure 8. Comparisons of the SMD for the viscosity and surface tension perturbation cases at 900 $\mathrm{K}, 22.8 \mathrm{~kg} / \mathrm{m}^{3}$. 


\section{UNCLASSIFIED}

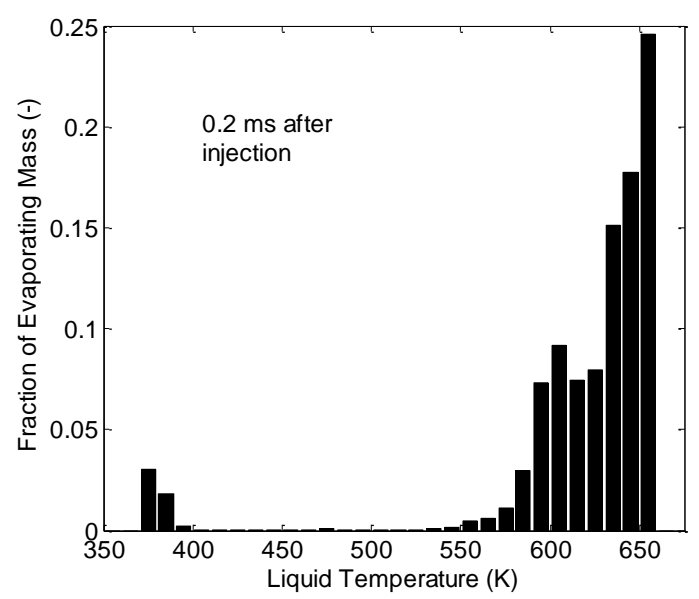

Figure 9. The evaporating mass fraction of each liquid droplet relative to the total evaporating mass at $0.2 \mathrm{~ms}$ after start of injection for the $900 \mathrm{~K}, 22.8 \mathrm{~kg} / \mathrm{m}^{3}$ case.

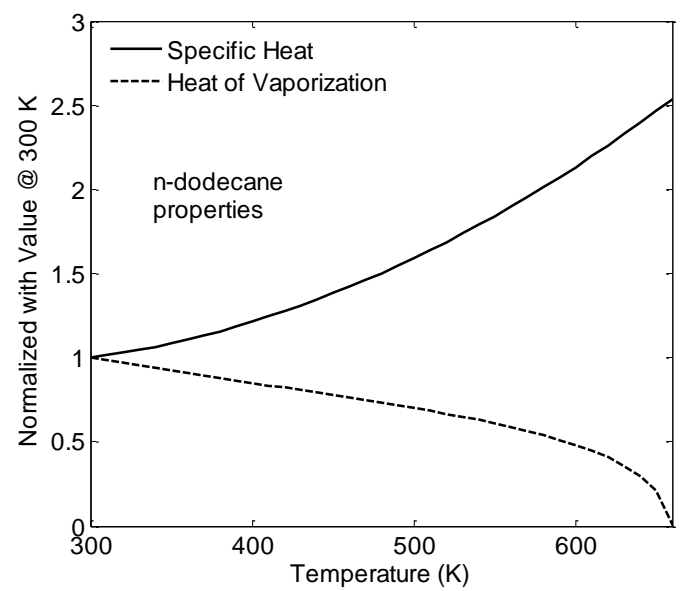

Figure 10. Temperature-dependent specific heat and heat of vaporization of liquid n-dodecane normalized to the $300 \mathrm{~K}$ value. 


\section{UNCLASSIFIED}
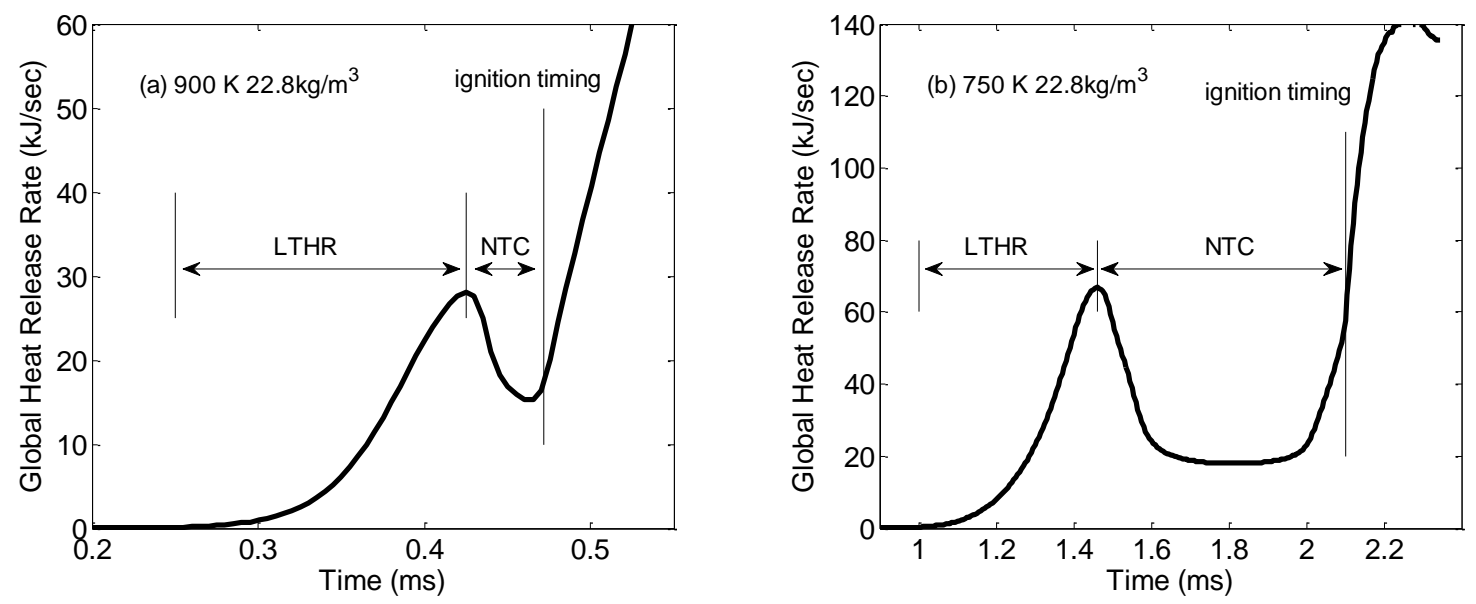

Figure 11. Calculated global heat release rates at (a) $900 \mathrm{~K}, 22.8 \mathrm{~kg} / \mathrm{m}^{3}$ and (b) $750 \mathrm{~K}, 22.8$ $\mathrm{kg} / \mathrm{m}^{3}$ for the baseline cases. The ignition timing shown on the figure is defined as the time of the maximum rise rate of peak temperature. The baseline ignition delay is $0.47 \mathrm{~ms}$ for (a) and $2.10 \mathrm{~ms}$ for (b).

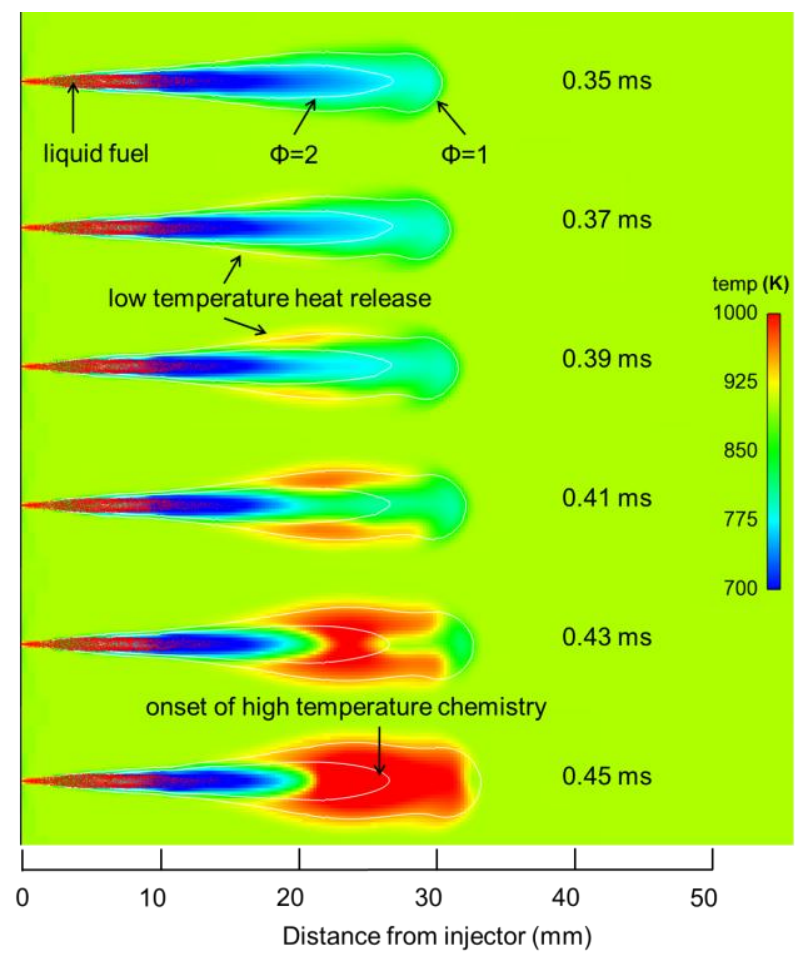

Figure 12. Calculated local temperatures and equivalence ratio contours at $900 \mathrm{~K}, 22.8 \mathrm{~kg} / \mathrm{m}^{3}$ with the baseline fuel properties. 


\section{UNCLASSIFIED}

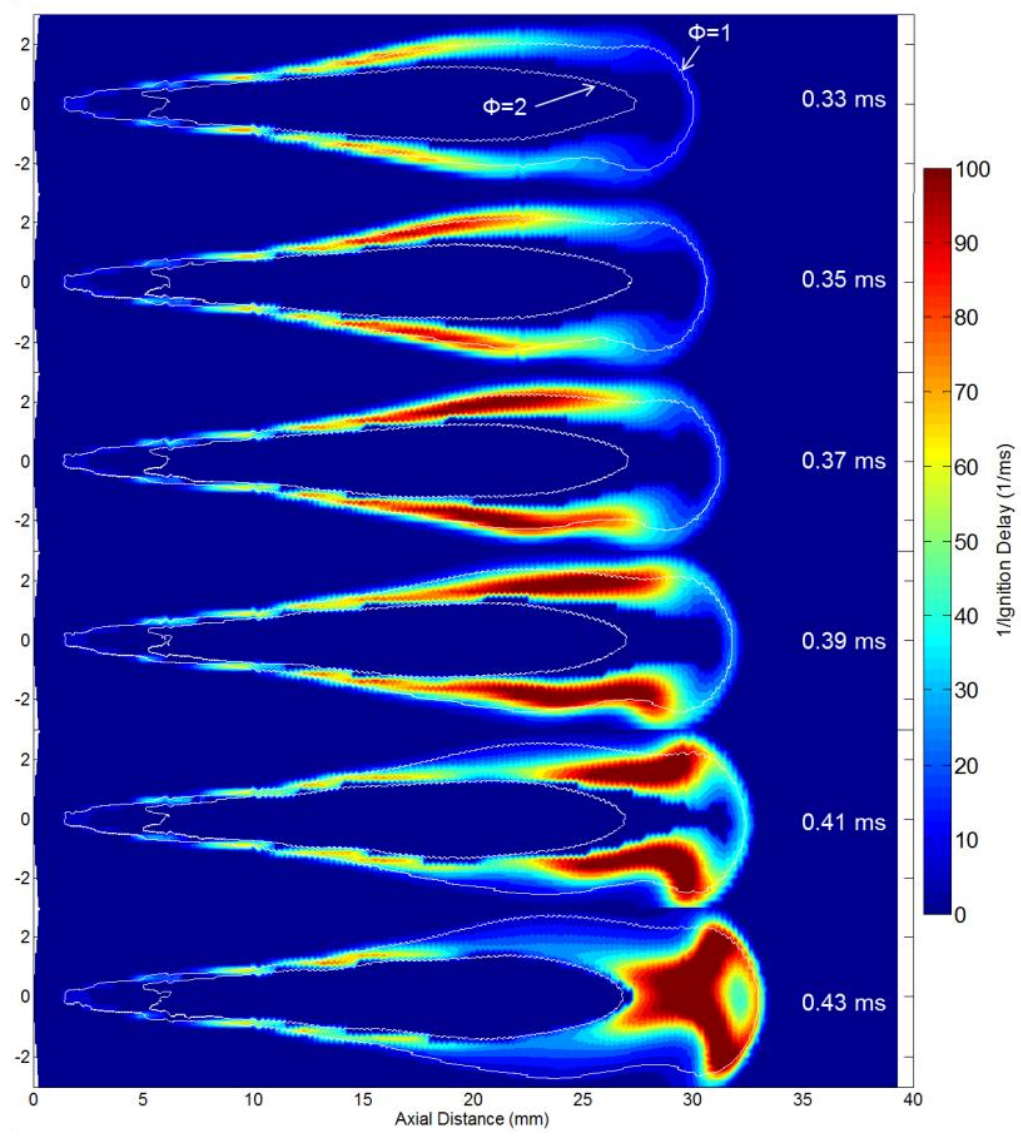

Figure 13. The local reactivity distributions and equivalence ratio contours during LTHR at $900 \mathrm{~K}, 22.8 \mathrm{~kg} / \mathrm{m}^{3}$ with the baseline fuel properties. 


\section{UNCLASSIFIED}
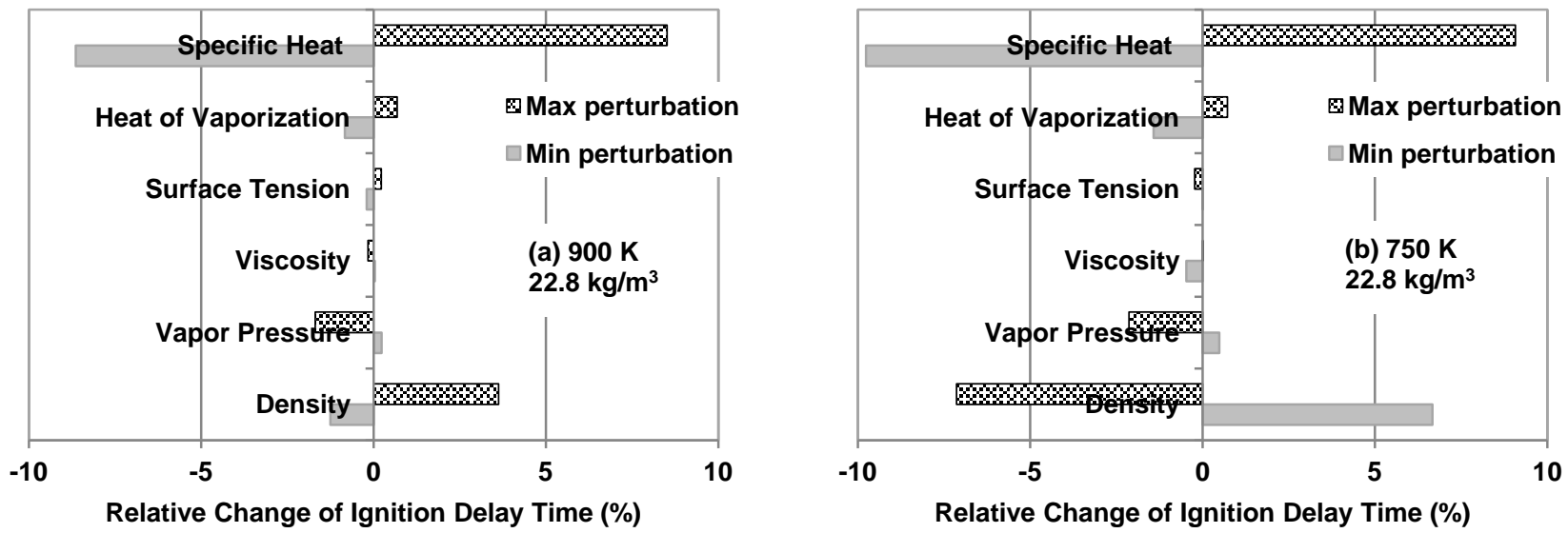

Figure 14. Relative change in ignition delay time due to physical property perturbations at (a) $900 \mathrm{~K}, 22.8 \mathrm{~kg} / \mathrm{m}^{3}$ and (b) $750 \mathrm{~K}, 22.8 \mathrm{~kg} / \mathrm{m}^{3}$. The baseline ignition delay is $0.47 \mathrm{~ms}$ for (a) and $2.10 \mathrm{~ms}$ for (b).
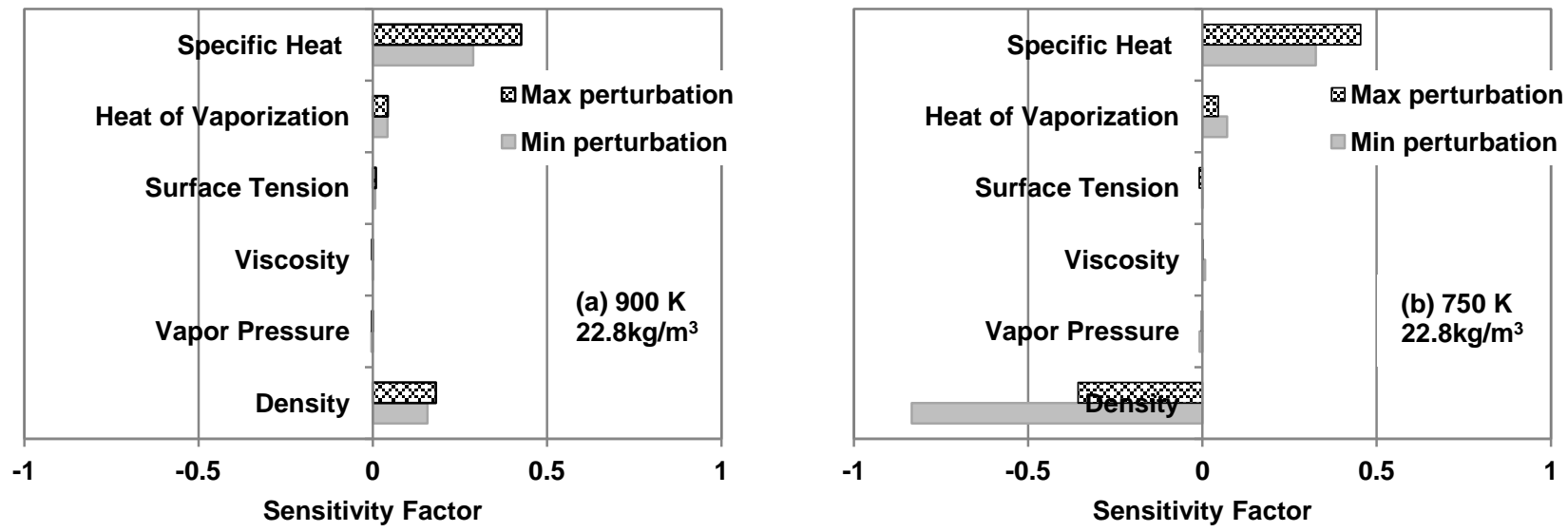

Figure 15. The sensitivity factor for ignition delay time due to physical property perturbations at (a) $900 \mathrm{~K}, 22.8 \mathrm{~kg} / \mathrm{m}^{3}$ and (b) $750 \mathrm{~K}, 22.8 \mathrm{~kg} / \mathrm{m}^{3}$. 


\section{UNCLASSIFIED}
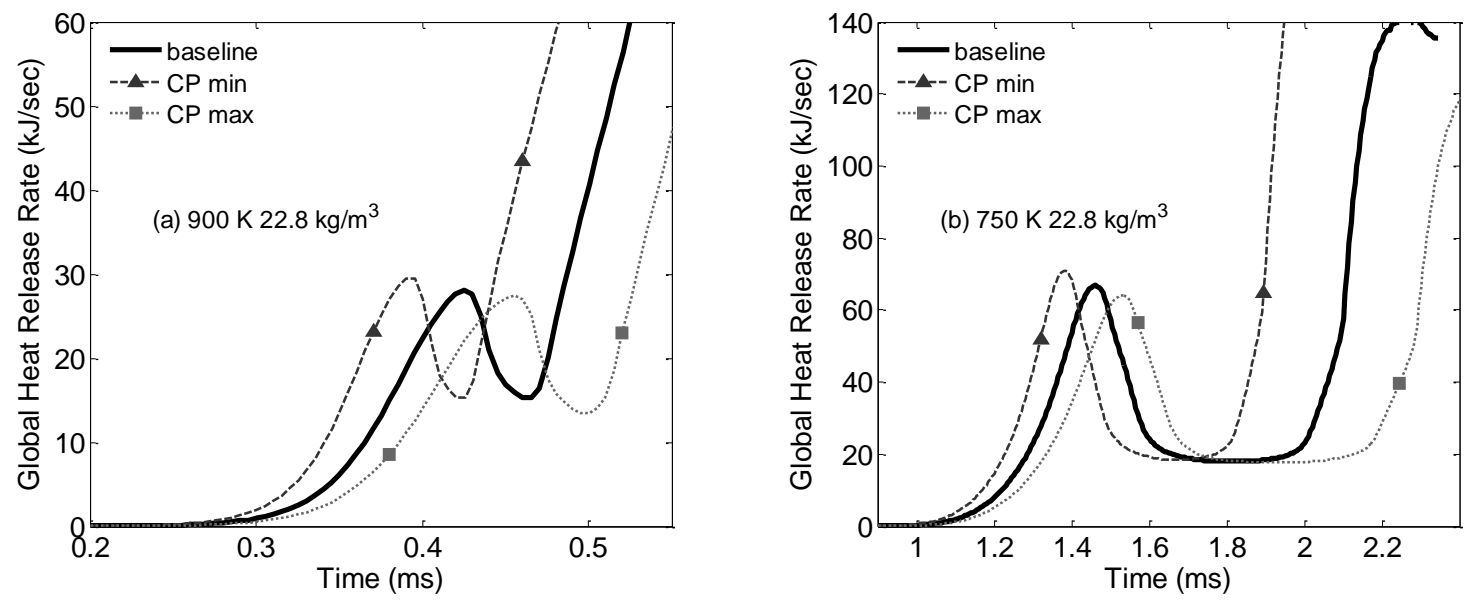

Figure 16. Comparisons of the calculated global heat release rates for the specific heat perturbation cases at (a) $900 \mathrm{~K}, 22.8 \mathrm{~kg} / \mathrm{m}^{3}$ and (b) $750 \mathrm{~K}, 22.8 \mathrm{~kg} / \mathrm{m}^{3}$.

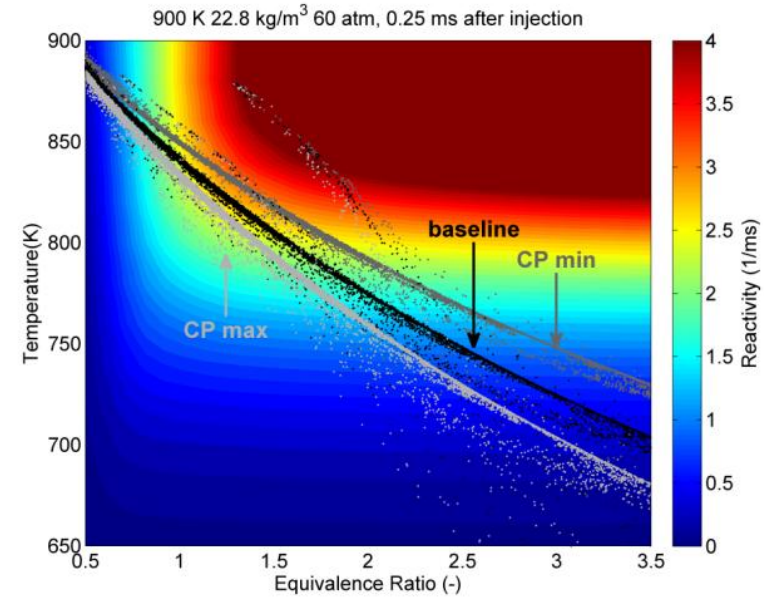

(a)

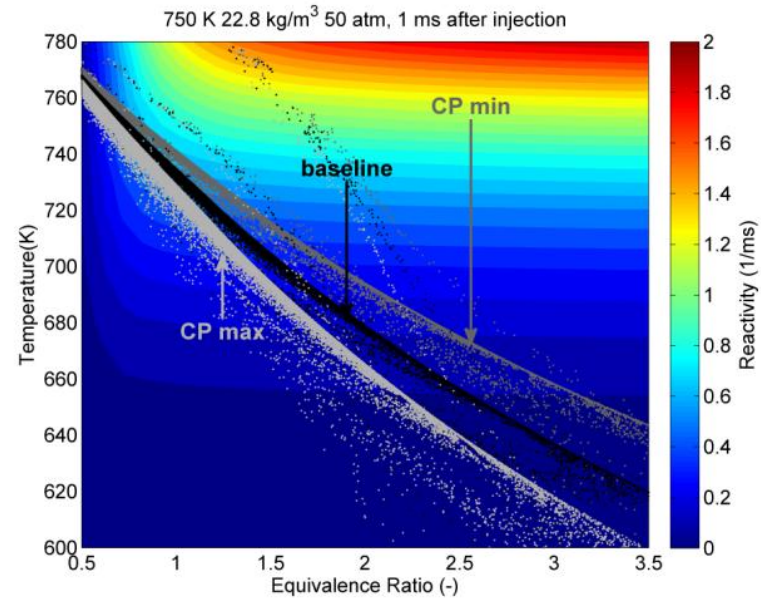

(b)

Figure 17 . The n-dodecane reactivity contour and temperature-equivalence ratio distribution within the spray before the start of LTHR for the specific heat perturbation cases. (a) $900 \mathrm{~K}$, $22.8 \mathrm{~kg} / \mathrm{m}^{3}$ at $0.25 \mathrm{~ms}$ after injection with the reactivity contour at $60 \mathrm{~atm}$ and (b) $750 \mathrm{~K}$, $22.8 \mathrm{~kg} / \mathrm{m}^{3}$ at $1 \mathrm{~ms}$ after injection with the reactivity contour at $50 \mathrm{~atm}$. 


\section{UNCLASSIFIED}
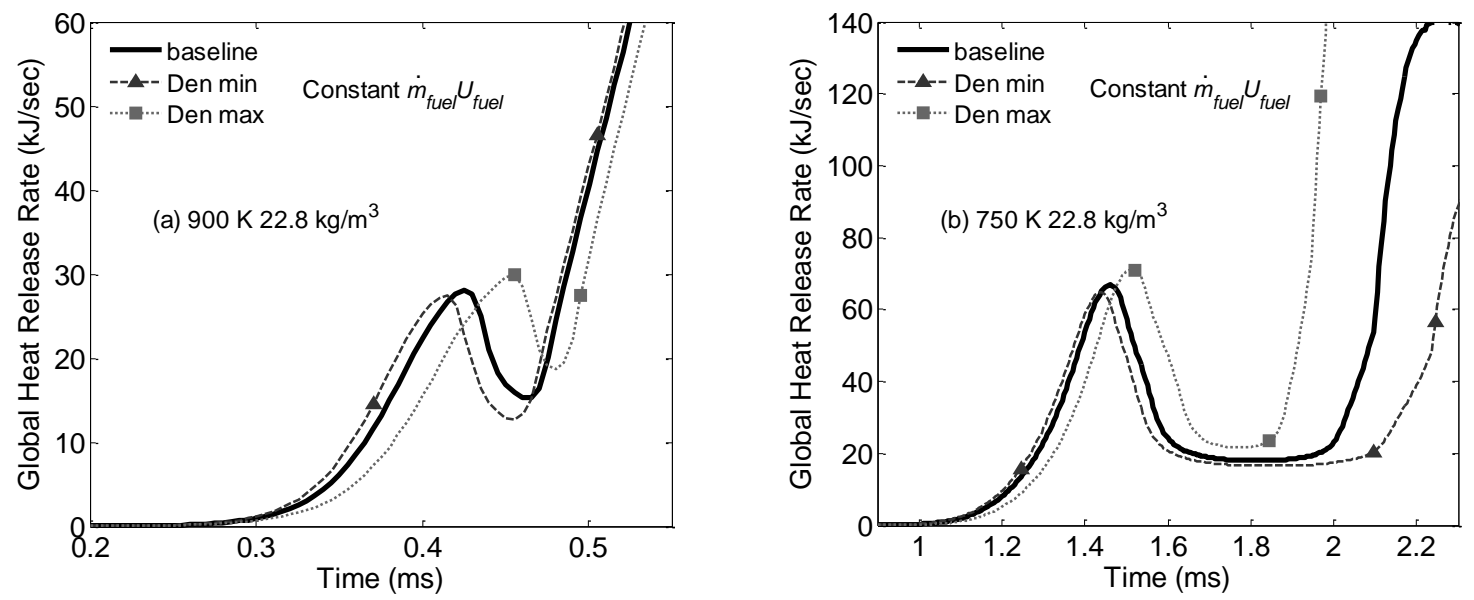

Figure 18. Comparisons of the calculated global heat release rates for the density perturbation with constant injection momentum at (a) $900 \mathrm{~K}, 22.8 \mathrm{~kg} / \mathrm{m}^{3}$ and (b) $750 \mathrm{~K}, 22.8 \mathrm{~kg} / \mathrm{m}^{3}$.

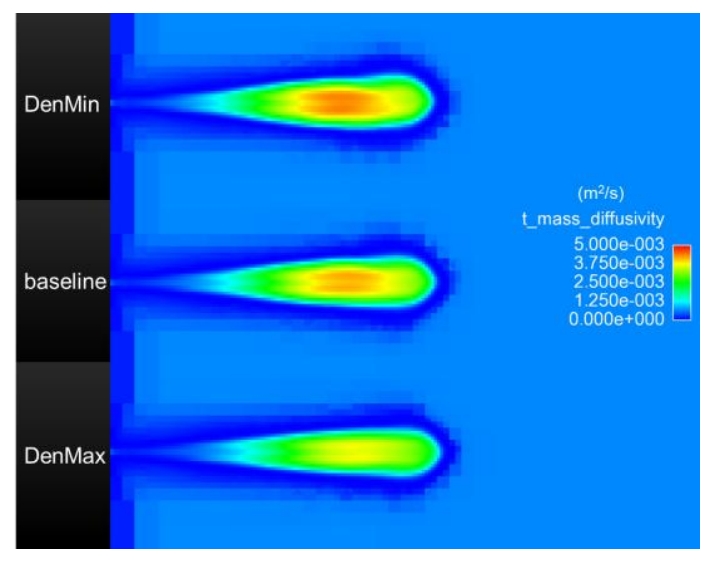

(a)

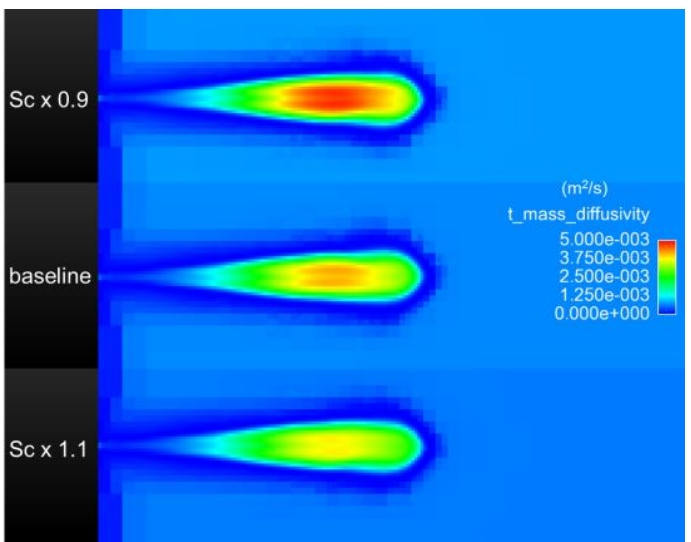

(b)

Figure 19. Comparisons of turbulent mass diffusivity for the $900 \mathrm{~K}, 22.8 \mathrm{~kg} / \mathrm{m}^{3}$ case at $0.25 \mathrm{~ms}$ after the start of injection of (a) density perturbation cases with constant injection momentum, and (b) mixing perturbation cases. 


\section{UNCLASSIFIED}
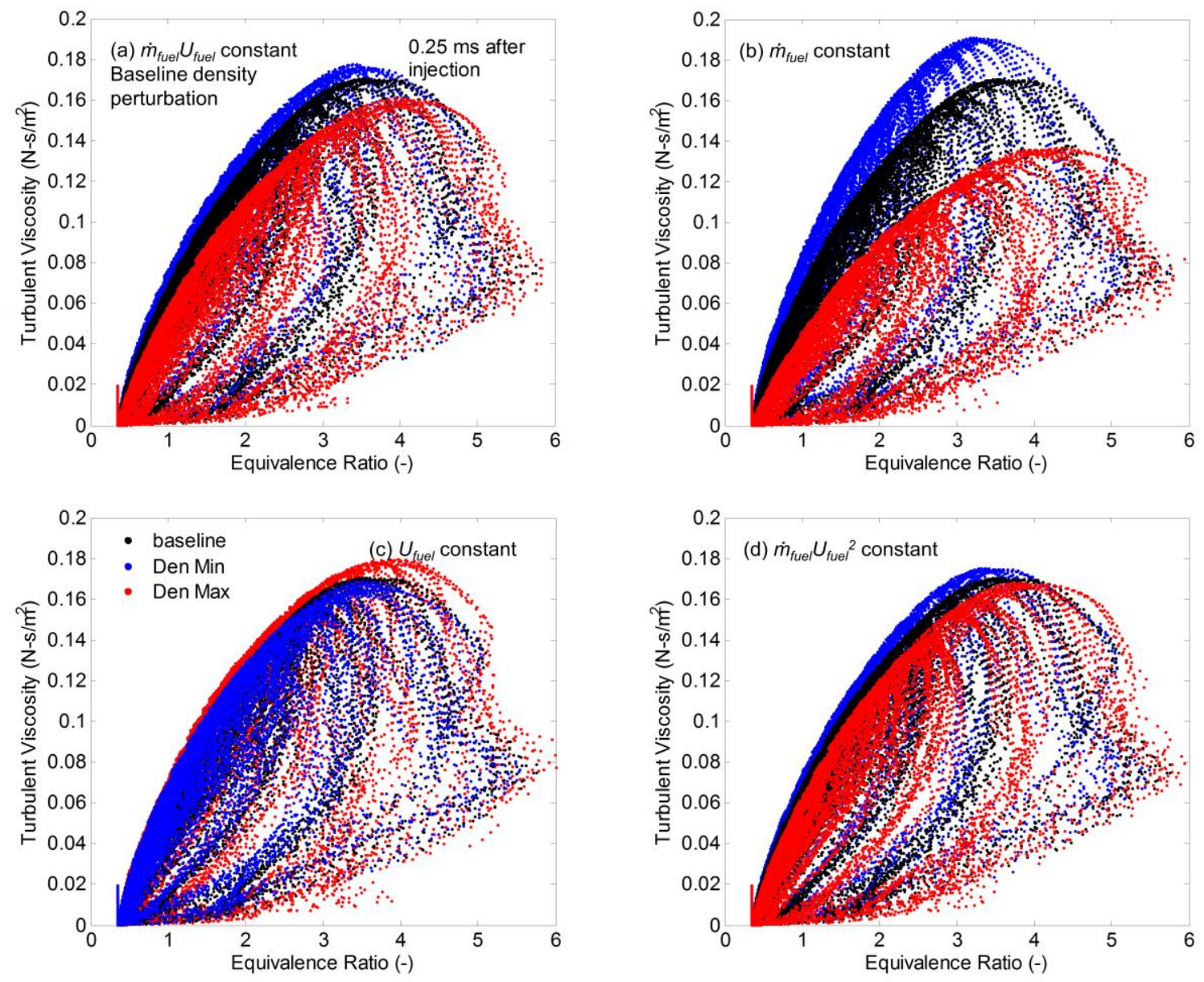

Figure 20. Comparisons of turbulent viscosities for the $900 \mathrm{~K}, 22.8 \mathrm{~kg} / \mathrm{m}^{3}$ case at $0.25 \mathrm{~ms}$ after the start of injection from different density perturbation methods. In (a) the momentum flow rate is held constant, (b) the mass injection rate is held constant, (c) the injection velocity is held constant, and (d) the kinetic energy flow rate from injection is held constant. 


\section{UNCLASSIFIED}
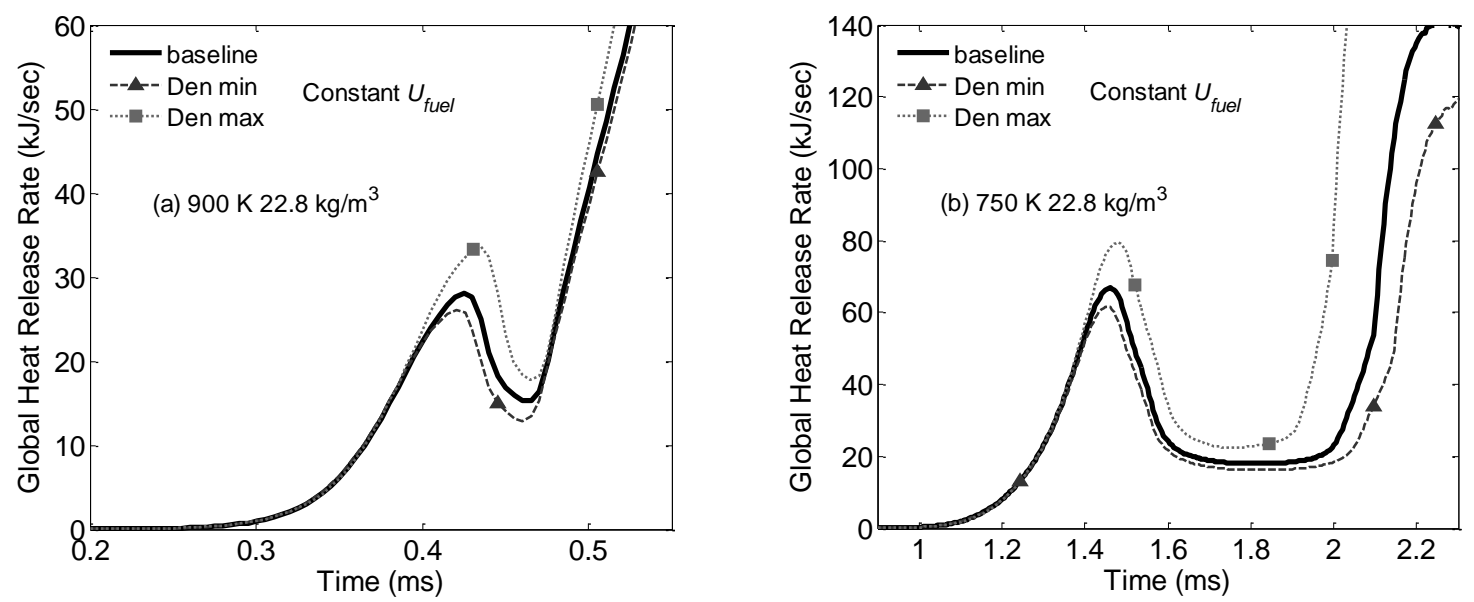

Figure 21. Comparisons of the calculated global heat release rates for the density perturbation with constant injection velocity at (a) $900 \mathrm{~K}, 22.8 \mathrm{~kg} / \mathrm{m}^{3}$ and (b) $750 \mathrm{~K}, 22.8 \mathrm{~kg} / \mathrm{m}^{3}$.

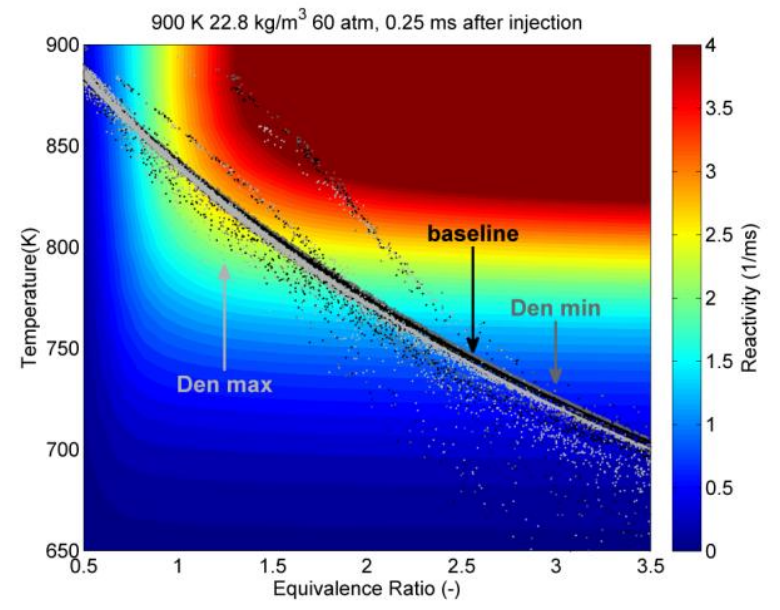

(a)

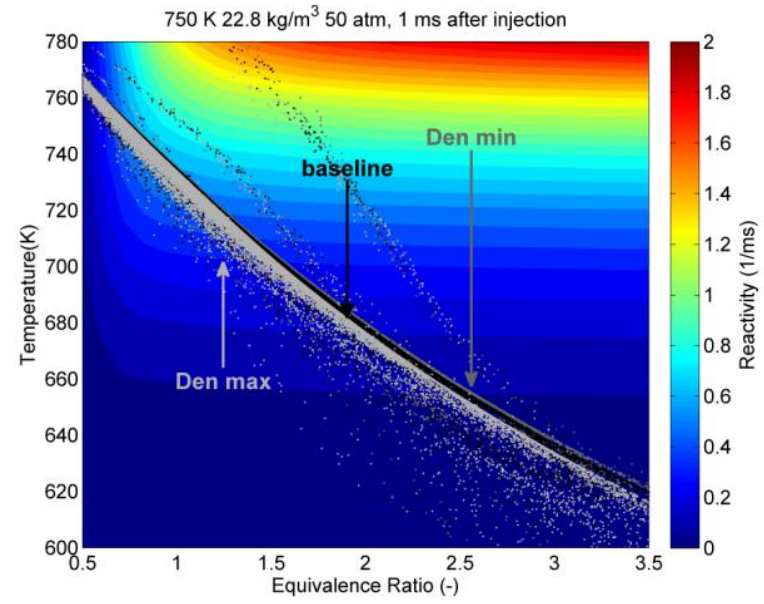

(b)

Figure 22. The n-dodecane reactivity contour and temperature-equivalence ratio distribution within the spray before the start of LTHR for the density perturbation with constant injection momentum. (a) $900 \mathrm{~K}, 22.8 \mathrm{~kg} / \mathrm{m}^{3}$ at $0.25 \mathrm{~ms}$ after injection with the reactivity contour at 60 atm and (b) $750 \mathrm{~K}, 22.8 \mathrm{~kg} / \mathrm{m}^{3}$ at $1 \mathrm{~ms}$ after injection with the reactivity contour at $50 \mathrm{~atm}$. 


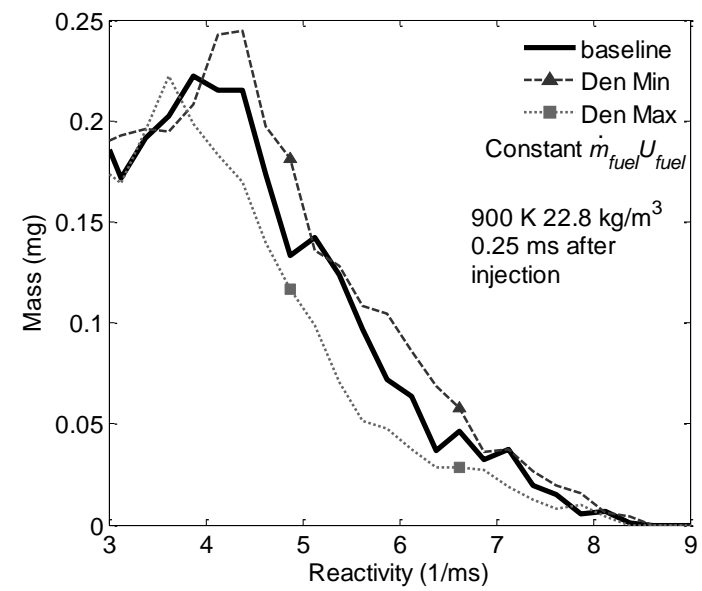

(a)

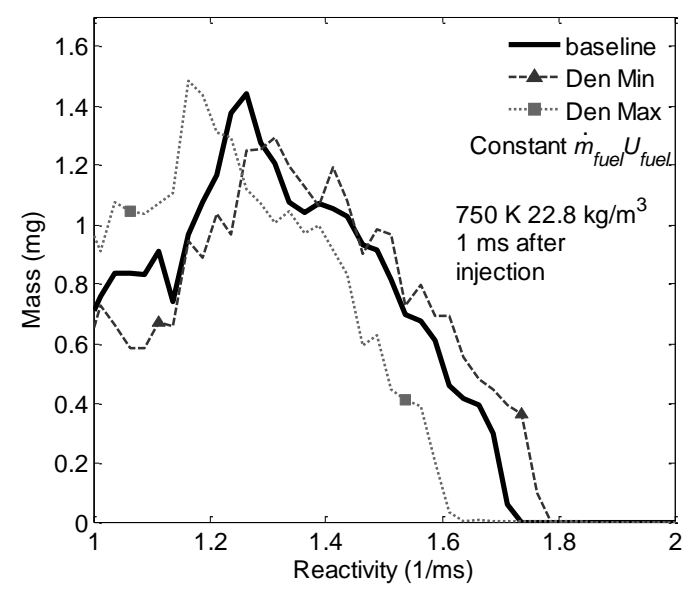

(b)

Figure 23. Mixture mass distributions in the local reactivity domain just prior to the start of low temperature heat release for the density perturbation with constant injection momentum for (a) $900 \mathrm{~K}, 22.8 \mathrm{~kg} / \mathrm{m}^{3}$ at $0.25 \mathrm{~ms}$ after injection and (b) $750 \mathrm{~K}, 22.8 \mathrm{~kg} / \mathrm{m}^{3}$ at $1 \mathrm{~ms}$ after injection. The reactivity bin size is 0.25 and $0.0251 / \mathrm{ms}$ for the $900 \mathrm{~K}$ case and the $750 \mathrm{~K}$ case, respectively.

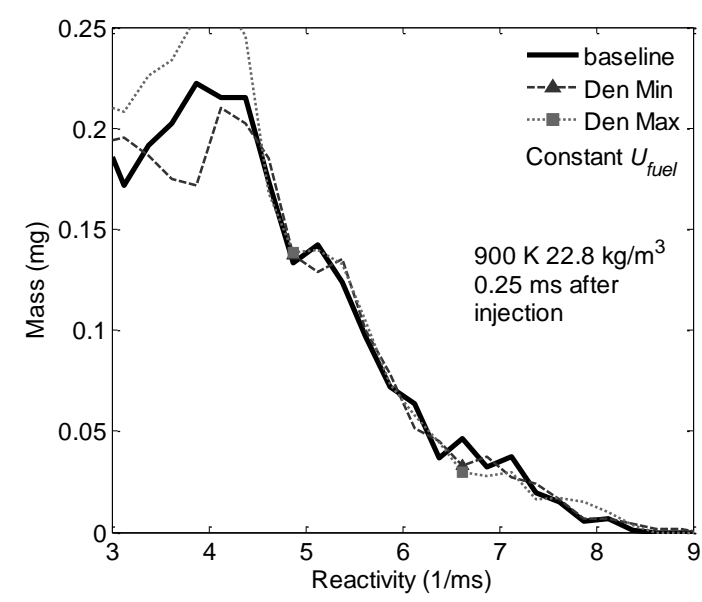

(a)

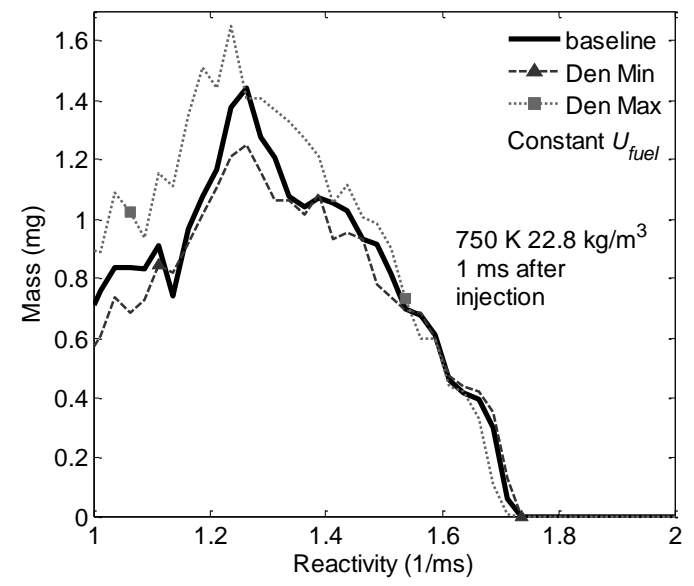

(b)

Figure 24. Mixture mass distribution in the local reactivity domain just prior to the start of low temperature heat release for the density perturbation with constant injection velocity for (a) 900 $\mathrm{K}, 22.8 \mathrm{~kg} / \mathrm{m}^{3}$ at $0.25 \mathrm{~ms}$ after injection and (b) $750 \mathrm{~K}, 22.8 \mathrm{~kg} / \mathrm{m}^{3}$ at $1 \mathrm{~ms}$ after injection. The reactivity bin size is 0.25 and $0.0251 / \mathrm{ms}$ for the $900 \mathrm{~K}$ case and the $750 \mathrm{~K}$ case, respectively. 


\section{UNCLASSIFIED}

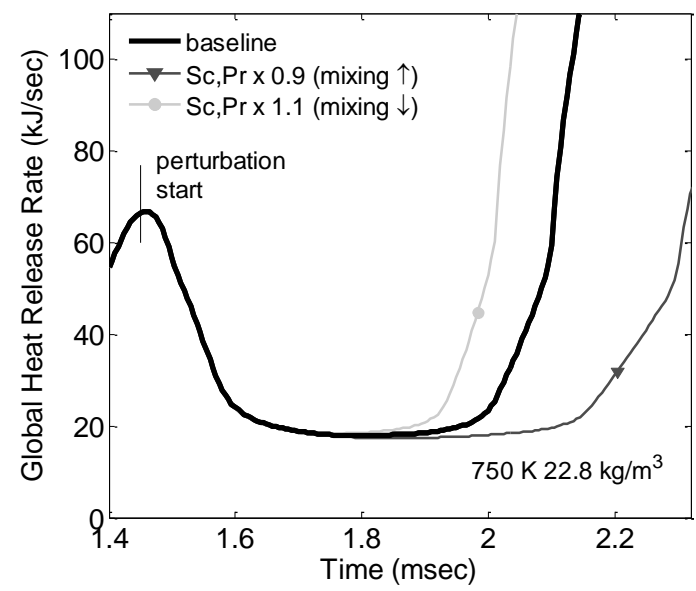

(a)

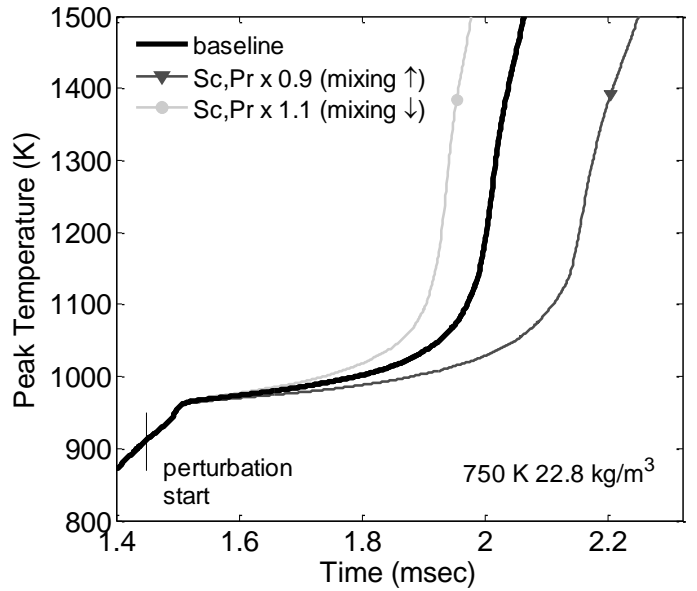

(b)

Figure 25. (a) Global heat release rate and (b) peak temperature within the computational domain of the mixing perturbation study during the NTC period at $750 \mathrm{~K}, 22.8 \mathrm{~kg} / \mathrm{m}^{3}$.

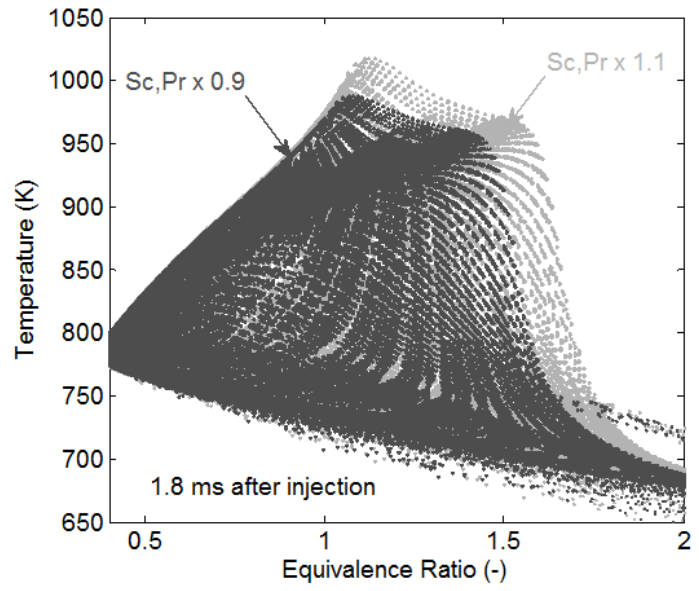

Figure 26. Temperature - equivalence ratio distributions at $1.8 \mathrm{~ms}$ after start of injection for the mixing perturbation cases in Figure 25. 


\section{UNCLASSIFIED}
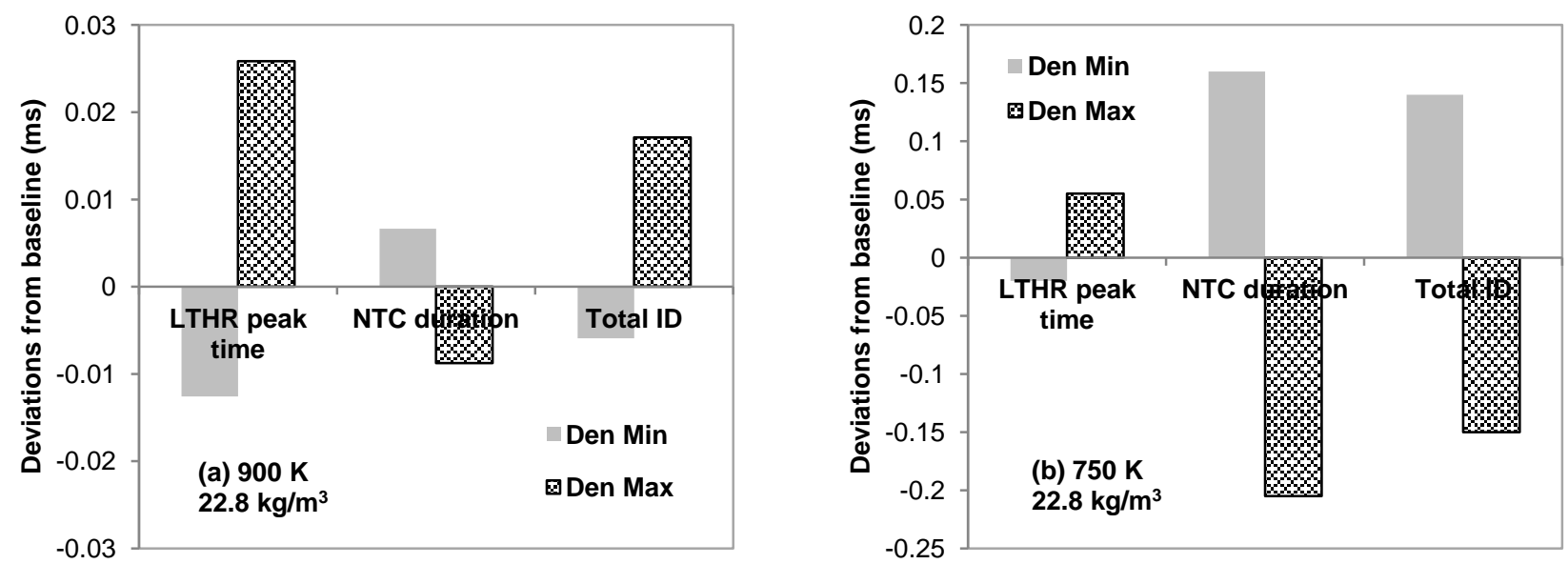

Figure 27. Deviations from the baseline in LTHR peak timing, NTC duration, and total ignition delay time for the density perturbation cases at (a) $900 \mathrm{~K}, 22.8 \mathrm{~kg} / \mathrm{m}^{3}$ and (b) $750 \mathrm{~K}, 22.8 \mathrm{~kg} / \mathrm{m}^{3}$. The deviation in total ignition delay time is the sum of the deviations in LTHR peak timing and NTC duration. The contribution from LTHR is greater for the $900 \mathrm{~K}$ case, but dominated by the contribution from NTC duration for the $750 \mathrm{~K}$ case. 